Portland State University

PDXScholar

Dissertations and Theses

Dissertations and Theses

Spring 6-20-2018

\title{
What's New Pussyhat? Men, Feminism, and Social Identity
}

Rachel Lee Crist

Portland State University

Follow this and additional works at: https://pdxscholar.library.pdx.edu/open_access_etds

Part of the Communication Commons, Feminist, Gender, and Sexuality Studies Commons, and the Sociology Commons

Let us know how access to this document benefits you.

\section{Recommended Citation}

Crist, Rachel Lee, "What's New Pussyhat? Men, Feminism, and Social Identity" (2018). Dissertations and Theses. Paper 4477.

https://doi.org/10.15760/etd.6361

This Thesis is brought to you for free and open access. It has been accepted for inclusion in Dissertations and Theses by an authorized administrator of PDXScholar. Please contact us if we can make this document more accessible: pdxscholar@pdx.edu. 


\title{
What's New Pussyhat?
}

Men, Feminism, and Social Identity

\section{by}

\section{Rachel Lee Crist}

\section{A thesis submitted in partial fulfillment of the} requirements for the degree of

\author{
Master of Science \\ in \\ Communication
}

\author{
Thesis Committee: \\ Lauren Frank, Chair \\ Jeffery Robinson \\ Steve Thorne
}

\section{Portland State University 2018}


(C) 2018 Rachel Lee Crist 


\begin{abstract}
Current understandings of feminism do not seek to dissuade men from feminism as a movement; moreover, men's inclusion in the feminist movement is seen as paramount to achieving equality and dismantling all forms of hegemonic power. Past research has shown that identification with a social movement is a strong predictor for participation in social change, more so than belonging to a disadvantaged social category. Despite this, there is nascent literature on how men define, identify as, and practice feminism. This study draws from a thematic analysis of three focus groups of self-identified males to investigate their self-identification as feminist. Using social identity theory, the analysis reveals the varied and nuanced ways participants define and understand feminism. The analysis further reveals how men construct their role in feminism and feel they can participate in the feminist movement. Participants expressed feeling excluded from feminism, despite noting that current articulations of feminism aim to include men. Additionally, participants expressed they could enact a feminist practice without identifying as a feminist. Overall, these findings illuminate some of the ways men possibly identify with the feminist movement and negotiate identifying as a feminist. This study illustrates that men's relationship to feminism is influenced not only by their own identities, but also by the perception of others. This study also raises the question of how well social identity theory captures the effect of perceived acceptance by prototypical group members.
\end{abstract}




\section{Dedication}

Austin, thank you for all the support and encouragement. WWWBWGWM. 
Table of Contents

Abstract....................................................................

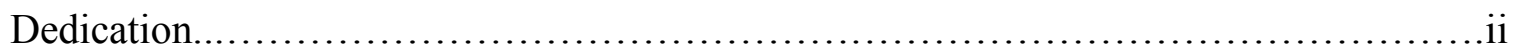

Chapter 1: Introduction.......................................................

Chapter 2: Literature Review............................................9

Chapter 3: Methods........................................................ 33

Chapter 4: Results.......................................................48

Chapter 5: Discussion................................................... 74

References...........................................................93

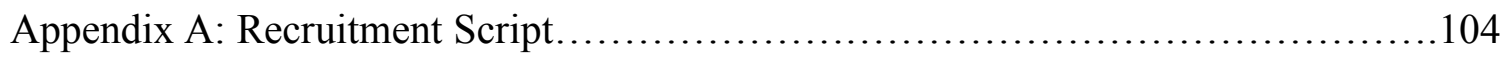

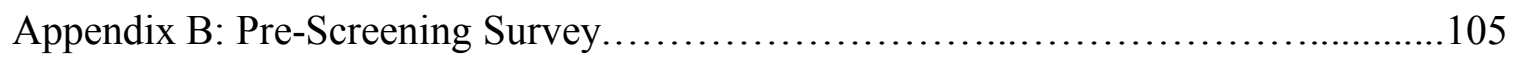

Appendix C: Moderator's Guide................................................. 108 


\section{Chapter 1: Introduction}

Blue lockers backdrop six young men who pose with their hands pointed to their chest, highlighting the identical text they all wear blazoned across their chests, "WILD FEMINIST" (Acker, 2016). This is the image of six male Centennial High School student athletes standing in the boys' locker room in Gresham, Oregon that went viral in October 2016 (Acker, 2016; Vagianos, 2016). The photo, with the caption "Sexual assault is not locker room banter," was a response to then Republican presidential candidate Donald Trump's defense of released recordings of his misogynistic comments about assaulting women (Acker, 2016; Vagianos, 2016). In interviews about the reason for the photo, senior Rhys Atkinson stated that, "It's very important to speak out about this, because it has to be known that there are men out there that support women and women's rights" (Vagianos, 2016, para. 6).

By actively identifying as feminist, Atkinson, who "believe[s] in the equality of everyone," and his fellow athletes are making a powerful statement not only the about treatment of women, but about who gets to be a feminist (Vagianos, 2016, para. 6). While this may not seem revolutionary, feminism has long been understood as a women's issue, an understanding that is reflected in both research and society (Herbert, 2007; Holmgren \& Hearn, 2009; McCbe, 2005; Wiley, Srinivasan, Finke, Firnhaber, \& Shilinsky, 2012; Tarrant, 2009; Toller, Suter, \& Trautman, 2004; Twenge \& Zucker, 1999; Zucker, 2004; Zucker \& Bay-Cheng, 2010). In a 2015 national poll conducted by the Washington Post and the Kaiser Family Foundation, 33\% of men identified as either a feminist or strong feminist, compared to $60 \%$ of women. In the same poll, $50 \%$ of men did not identify as 
feminist and an additional 5 percent identified as anti-feminist (Washington Post-Kaiser Family Foundation, 2015). As "men are the primary agents in maintaining and supporting sexism and sexist oppression" (hooks, 2000b, p. 83), sexism and sexist oppression can only be addressed through men's efforts to transform their awareness and society as a whole; women cannot achieve this change on their own.

Feminists increasingly invite men to partake in the movement, not only calling for support, but also calling attention to how current hegemony is also detrimental to men's lives (hooks, 2000b; Herbert, 2007). In the book The Feminist Fight Club, a guide for women on how to combat subtle forms of sexism in professional environments, author Jessica Bennett dedicated a section to male allies, providing suggestions for how they can actively contribute to women's liberation. In this brief section, Bennett (2016) directly stated that men are essential in dismantling the patriarchy and that doing so will benefit women and men. This is a direct call for men to engage with feminism, yet it is couched in a book designed to appeal to women. While Bennett (2016) stated that greater equality between men and women is beneficial to both, she identified men as "comrades" rather than including them in the feminist identity.

Per recent iterations of feminism, a common goal of the feminist movement - as it is understood today - is to create a society where individual behavior and ability are not bound by socially constructed polarizing conceptualizations of gender. In other words, feminism works to dismantle the patriarchy, as the current social structure limits individuals in their access to work, equal pay, social mobility and emotional/physical expression of themselves. More recent versions of feminism work to break down the 
gender binary present in our society, which is restrictive for both women and men. Although the oppressive force of the patriarchy has predominantly been understood to fall heaviest on women, the exertion of this force on men has received less focus. However, feminism scholars, such as bell hooks, have noted that the patriarchy does not benefit all men equally and that the dismantling of the patriarchy would be equally beneficial for men as it would for women (Herbert, 2007; hooks, 2000a, 2000b; Tarrant, 2009).

While such academic articulations of the feminist movement do not exclude men, popular understandings largely fail to include men. This presents problems for a movement that understands gender as fluid and works towards individuals not being defined by their gender. While it is important to highlight the experiences of the systematically disadvantaged, the singular focus on women's experiences reinforces the gender binary that academic feminism argues against (hooks, 2000b). Men, as the dominant group and primary benefactors of the current social structure, have received less scholarly attention to their experiences and their degree of engagement with feminism(s). Patriarchy restricts men's ability for self-expression. Just as patriarchy has created social expectations within which women are expected to conform, so too have restrictive expectations been created for men (Kimmel, 2005). Race, class, sexual orientation, and other factors aside from gender identity also affect an individual's lived experience and simultaneously affect how they experience oppression and privilege (Dill, McLaughin, \& Nieves, 2007). The understanding that people "live multiple, layered identities" as a result of the interplay of these different factors was coined 
intersectionality (Dill, McLaughin, \& Nieves, 2007, p. 629). Thus, while the patriarchy is largely beneficial to men, it does not negate the existence of racial, class, and other privileges (hooks, 2000b). With the advent of intersectionality, the concept that people hold multiple identities which interact and contribute to their lived experiences, the limitations of categorizing an individual based on a single feature of their identity have become apparent (Brah \& Phoenix, 2004).

Feminism has largely been understood to be a female-oriented movement (Herbert, 2007; hooks 2000b), and while this has often been the focus of many iterations of the movement, current feminisms have a broader focus. The failure of more general conceptualizations of feminism to grasp this broadening limits the movement's effectiveness and ability to achieve its goals. The feminist movement is often classified as being primarily composed of women and is often negatively stigmatized. The combination of these factors restricts identification with the movement by both men and women alike (Breen \& Karpinski, 2008; Zucker \& Bay-Cheng, 2010). Despite ideological alignment among both women and men, many men would reject the moniker of feminist (Breen \& Karpinski, 2008; Zucker \& Bay-Cheng, 2010). This is important as increased identification with a group has been shown to correspond to increased likelihood of social action and protest on the behalf of that group (Klandermans, Sabucedo, Rodriguez, \& De Weerd, 2002; van Stekelenburg \& Klandermans, 2013; van Zomeren, Postmes, \& Spears, 2008). Thus, failure to identify with a movement and take up the mantle of feminist, despite holding what have been deemed feminist values is problematic for a movement intending to enact social change. 
Identification with a social movement is a strong predictor of an individual's intention to participate in social action, more so than belonging to a disadvantaged social category (van Zomeren, Postmes, \& Spears, 2008). Thus, identification with social movements is key to enacting social change to combat social issues. Since identification with social movements has been found to be a stronger indicator of participation in social action than identification with social categories, it matters less if an individual does not identify with a disadvantaged social category (van Stekelenberg \& Klandermans, 2013). Rather it is their identification as part of the social movement that is vital in creating social action that supports the goals of a social movement. Feminism has come up against a barrier in that "women acting alone are not enough to oppose the momentum of the prevailing social arrangement or to galvanize a critical mass of society willing to adopt new behaviors and interactions" (Herbert, 2007, p. 41).

For social mobilization to occur, there must be participation in social action groups (Hogg, 2006). Hogg (2006) asserts that it is unlikely that people will behave as part of a group when they lack of a sense of belonging or identification with that group. "People can be in a common-bond or common-identity group, but if they have no sense of belonging, do not identify, and do not define and evaluate self in terms of the properties of the group, then they are unlikely to think, feel, and behave as group members" (Hogg, 2006, p. 117). For the feminist movement, as it is currently understood, to succeed in the elimination of gender-based injustices, men need to be able to identify as feminists. Despite the necessity of men's engagement with feminism, the majority of 
existing research on identification with feminism, while not ignoring men entirely, has focused on women.

The 2017 Women's March on Washington D.C. whose organizers' stated mission was "to harness the political power of diverse women and their communities to create transformative social change" (Women's March, n.d., para. 1), has been largely associated with feminism and often understood as a feminist movement. The Women's March was criticized for unclear guiding principles, a critique that while ameliorated, was never fully resolved paralleling feminism's own contested definitions. Regardless of the struggle over clear guiding principles, the 2017 Women's March on Washington, D.C. and the multitude of solidarity marches held across the United States and across the world, made a massive visual statement in response to the election of Trump. In Time Magazine's cover article, which featured a lone, pink pussyhat, noted that Trump's “locker-room banter" gave the Women's March “its palette (pink), its signature attire (the pussy hat) and its rules of engagement" (Vick, 2017, para. 8). The Pussyhat Project was created in order to provide a visible representation highlighting solidarity in people's support for women's rights whether or one was able to attend a Women's March (Pussyhat Project, 2016, para. 4).

The object that became the emblem for this movement still bears the question of who can wear a pussyhat. The project's website directly states that "anyone who supports women's rights is welcome to wear a Pussyhat," directly followed with the statement that "Feminists wear Pussyhats. And lots of different people are feminists" (Pussyhat Project, n.d., para. 5). While this assertion could be seen as widely inclusive, the following 
paragraph specifically and solely focuses on non-gender conforming people's ability to be feminists. While the project states that "people with any genital anatomy can be feminists," the context in which it does so leaves it ambiguous as to whether individuals that identify as men, and not as women, are included in their assertion (Pussyhat Project, n.d., para. 5). Based on the information on the Pussyhat Project's website, it is ambiguous whether or not men are included within the Pussyhat Project and allowed to authentically adorn a pussyhat, a visual signal of solidarity with the Women's March and, more broadly, feminism. That being said, men were present at Women's Marches across the United States and globally.

The purpose of this study is to investigate men's self-identification as feminists. Given the importance of identification with groups in working towards social change, the ability and the extent to which men identify with feminism as a social group is an important factor in the feminist movement's ability to enact social change to the benefit of both men and women. Chapter 2 presents a review of the literature to provide a theoretical background on social identity theory (SIT) while establishing a historical overview of the feminist movement and studies of men's identification as feminist. Chapter 3 establishes the methods employed in this research, including the participants involved in this study, procedure, and basis for analysis. Chapter 4 details the focus group conversations with regard to SIT, prototypical group members, and men's relationship with feminism. Chapter 5 provides an analysis of established feminist prototypes, men's identification with and practice of feminism, and posits an additional consideration for SIT. The analysis further reveals how men construct their role in feminism and feel they 
can participate in the feminist movement. Participants expressed both feeling excluded from feminism and the ability to enact a feminist practice without identifying as a feminist. Overall, this study illuminates some of the ways men possibly identify with the feminist movement and negotiate identifying as a feminist. Furthermore, this research illustrates that men's relationship to feminism is influenced not only by their own identities, but also by the perception of others. And it also raises the question of how well social identity theory captures the effect of perceived acceptance by prototypical group members. 


\section{Chapter 2: Literature Review}

As this study seeks to explore men's understanding of feminism and whether they feel able to self-identify as feminists, this chapter will provide contextual understanding for the study by first providing a brief historical overview of the feminist movement and the different feminisms of which it is comprised. In order to establish current context for the feminist movement, a more thorough exploration of feminism's third-wave will be provided along with intersectionality and the social construction of gender, both key aspects of present understandings of feminism. Further discussion will include a brief overview of postfeminism and an in-depth exploration of the relationship between men and the feminist movement. Following this, the theoretical framework for this study, social identity theory (SIT), will be discussed, and specific relevant elements of the theory highlighted. Finally, the chapter will discuss the difference between feminist attitudes and feminist identity as well as the resulting implications.

\section{Feminism}

Feminism, as with any movement, has a sense of fluidity as it progresses and evolves through time. Perhaps this is why feminist theory is frequently discussed in terms of waves. These waves are largely defined in a temporal sense, but are determined by events, political sensibilities, and changes in thought. It is important to note that while the wave analogy facilitates the discussion of feminism's history, it is simultaneously problematic as it often fails to fully acknowledge the contributions made by women of color throughout (Springer, 2002). Given the rich and varied history of feminism, it is more correct to use "feminisms" rather than feminism, as a singular, agreed upon 
definition does not exist (Kearny, 2012). As there have been a multitude of feminist activisms and ideologies which led to multiple feminisms, these feminisms can be consider part of a general feminist movement which aims to eradicate gender oppression (Kearney, 2012). While some attribute the start of the first-wave feminism with the first full-scale women's rights convention in 1848 (Kinser, 2004), many attribute the start of first-wave feminism as corresponding to the women's suffrage movement (Alfonso \& Trigilio, 1997). Although women's suffrage is a more obvious historical marker, the beginnings of the women's suffrage movement and first-wave feminism stem from industrialization of the mid-1800s (Freedman, 2002; Kearney, 2012). Though the era of industrialization continued to disadvantage women, primarily through increasing the gap between women's unpaid labor and men's paid work, it also provided the necessary resources for women to challenge gender inequality (Freedman, 2002). It is worth noting that feminists during this period were also demanding improvements for women's education, property rights, and health; whereas the suffrage movement focused specifically on legal barriers that prevented gender equality (Freedman, 2002; Kearney, 2012).

Second-wave feminism, inclusive of radical, liberal, and cultural feminisms, is largely rooted in the political climate of the 1960s and 1970s when women's liberation movements, having secured the right to vote, focused on advocating for women to achieve equality with men (Alfonso \& Trigilio, 1997; Kearney, 2012; Kinser, 2004). Highly influential to the feminisms of the second-wave was Simone de Beauvoir's Second Sex, which examined the dominant ideology that held women as the "other" in 
patriarchal society. Radical feminism emerged at the start of the second-wave and emphasized the division of labor in the United States, where women's labor remained unpaid and primarily in the private spheres (Alfonso \& Trigilio, 1997; Kearney, 2012). As radical feminism declined, the 1970s saw the rise of both liberal feminism and cultural feminism (Kearney, 2012). Liberal feminism primarily advocated for women's equality with men in public domains and vied to achieve this primarily through policy; although in doing so they neglected working to improve women's experiences in the private sphere (Freedman, 2002; Kearney, 2012). Following achievements made by liberal feminists, the mid-1970s saw the emergence of cultural feminism, which held that women were substantively different from men and attempted to counter women's subjugation by privileging women and femininity (Kearney, 2012).

While the boundary between first- and second-wave feminisms is not exact, it is more clearly demarcated than that of the transition from second- to third-wave feminism. Feminism's third-wave is often posited as developing in the political climate of the mid1980s to early-1990s, as feminism began to confront the issue of race (Kearney, 2004; Kinser, 2004). Womanism, black feminism, and women of color feminism gained greater attention in the 1980s having developed in response to feminism's focus on a single aspect of identity and failure to acknowledge the contributions of women of color throughout the history of feminism (Freedman, 2002; Kearney, 2012; Kinser, 2004). Black feminist writers championed the need for feminism to address external forms of oppression (i.e., the unjust exercise of authority and power by one group over another) while simultaneously interrogating internalized forms of oppression and discrimination 
(i.e., the internalized ideology of inferiority; Mann \& Huffman, 2005). These

explorations gave way to the development of intersectionality, the concept that an

individual's lived experience is the result of a composite of social categorizations (e.g., race, gender, class, etc.), which is seen as a significant break from second-wave feminism (Fernandes, 2010).

\section{Intersectionality}

The concept of intersectionality is largely credited as arising from feminism's development of a more complex understanding of women's experience, one that acknowledged that oppression could not be understood in terms of gender alone (Freedman, 2002). Intersectionality is seen as emerging from Kimberlé Williams Crenshaw's (1989) metaphor of intersecting streets in her work critiquing feminist theory for treating race and gender as unrelated categories of experience (Hancock, 2015). Crenshaw's (1989) work developed as a response to feminism's failure to recognize the multidimensional experiences of women of color. Fernandes (2010) defines intersectionality as "a series of cross-disciplinary interventions that analyzed the ways in which the intersection between inequalities such as race, gender, and class shaped women's lives and structured the social location of specific groups of women of color in distinctive ways" (p. 102).

According to Brah and Phoenix (2004), intersectionality signifies:

The complex, irreducible, varied and variable effects which ensure when multiple axes of differentiation -- economic, political, cultural, psychic, subjective and experiential --intersect in historically specific contexts. The concept emphasizes that different dimensions of social life cannot be separated out into discrete and pure strands. (p. 76) 
An understanding of individual experience can emerge through the acknowledgement of intersecting social constructs and how the interaction of these constructs positions an individual within society. Using intersectionality as a lens to look at individual experiences aims to prevent the marginalization of those whose experience does not fall within the narrow definition required by the generalization of experience needed in order to construct a category (Brah \& Phoenix, 2004; Hancock, 2013). Hancock (2013) posits intersectionality as a paradigm, and, using Patricia Hill Collin's (1990) definition, refers to intersectionality as an "analysis claiming that systems of race, social class, gender, sexuality, ethnicity, nation, and age form mutually constructing features of social organization" (as cited in Hancock, 2013, p. 261).

\section{Third-wave Feminism}

Mann and Huffman (2005) defined the emergence of third-wave feminism as "the rise of a new discourse or paradigm for framing and understanding gender relations that grew out of a critique of the inadequacies of the second wave" (p. 57). Following this line of thought, Snyder (2008) states that third-wave feminism has articulated three-major responses to theoretical issues with second-wave feminism. First, third-wave fronts an intersectional version of feminism; second, the influence of postmodernism resulted in the embracement of "multivocality over synthesis and action over theoretical justification"; and, third, "an inclusive and nonjudgmental approach that refuses to police the boundaries of the feminist political" (Snyder, p. 175).

The third-wave foregrounds "personal narratives that illustrate an intersectional and multiperspective version of feminism" in order to combat the previous wave's 
attempt at unifying women through a sense of a singular experience that ignored difference (Snyder, 2008, p. 175). This aligns with Butler's (1999) observation that an instable definition of women challenges feminism. Similarly, Lotz (2003) finds that thirdwave feminism works towards a subjective understanding and personalized definition of feminism, moving away from second-wave cultural and liberal feminist approaches that sought to unify the diverse category of women. This singular conceptualization of feminism attributed to the second-wave is "undermined by representational discourse in which it functions" (Butler, 1999, p. 7). Walker (2006) cites second-wave feminism as too restrictive an identity for "a generation that has grown up transgender, bisexual, interracial, and knowing and loving people who are racist, sexist, and other afflicted" (as cited in Snyder, 2008, p. 176).

Further disrupting the definition of women, third-wave feminists have embraced gender as a social construction (Butler, 1988; Kearney, 2012). Lorber (1991) put forth that the gender one is assigned at birth dictates social expectations of an individual and constitutes a person's masculinity or femininity, thus constructing gender. The social constructionist approach to gender has resulted in the third-wave advocating for "all individuals' access to the wide spectrum of gendered identities" (Kearney, 2012). Despite a more inclusive and varied definition of gender, third-wave feminism remains primarily the domain of women. Gender stereotypes play a large part in reinforcing society's expectations and roles for men and women. Thus, gender is a socially constructed concept that allows society to organize the way people view their lives, and helps govern the way people perform gender roles (Lorber, 1994). Butler (1988) argues that 
feminism's attempt to make women visible risks making apparent a category (i.e., women) that may not be representative of women, and doing so risks the reification of sexual differences that "unwittingly [preserve] a binary restriction on gender identity and an implicitly heterosexual framework for the description of gender, gender identity, and sexuality" (p. 530). According to Dill, McLaughlin and Nieves (2007), "the developing study of sexuality broadens our understanding of gender, breaking down some of the traditional borders between the sexes" (p. 631). Additionally, using an intersectional approach further illuminates the relationship between sexuality, power, identity, and social organization.

\section{Social Construction of Gender}

According to Butler (1988), gender is the cultural interpretation of biological sex; this claim aligns with Foucault's perspective that the body is a historical situation that reflects social and historical possibilities. Butler (1988) argues that gender is an identity that is created and perpetrated through repeated stylized acts; that is, the way one gestures, moves, and acts communicates and performs their gender. Likening these stylized acts to theatrical performance, Butler (1988) states that a person performing their gender is playing out a stylized act that communicates them "doing gender" through social performance, and thus creates social reality through acts like language, nonverbal communication, and "symbolic social sign[s]," all of which constitute performing gender. The repetition of gendered acts is a way of re-enacting and re-experiencing meanings that are established within society, which transmutes the performances into a legitimate form of behavior. Inspecting gender through this lens, Butler (1988) argues that individual 
bodies become stylized into performing these repetitive acts to convey their gender and follow social norms in order to reiterate their gender in public. Thus, gender is reified through repeated and sustained social performances (Butler, 1988). In establishing gender as a performance, Butler (1988) argues that gender is "real only to the extent that it is performed" (p. 527). Crawford (2002) establishes that gender is enforced by societal structure and, thus, internalized.

Lorber (1994) asserts that gender is a social institution that attributes certain roles to certain people, depending on what gender they were assigned at birth according to their biological sex. According to Lorber (1994), "individuals are born sexed but not gendered, and they have to be taught to be masculine or feminine" (p. 57). Thus, masculinity and femininity are learned behaviors. Since different genders are treated differently, being assigned a gender at birth based on biological sex affects a child's treatment by society which results in them feeling and acting differently further naturalizing gender differences. This ultimately influences their lived experiences, which constitutes a person's gender identity, and which they carry on into adolescence, adulthood and parenting (Lorber, 1994). It should be noted that both Butler (1988) and Lorber (1994) maintain that gender performance is regulated by society and failure to perform one's gender correctly is punished by society. The establishment of gender as socially constructed allows gender expression to break away from a binary expression that aligns with biological sex. In doing so, gender can be understood to exist along a spectrum with masculinity and femininity as opposing poles of gender expression. Additionally, the departure from biological sex no longer constrains gender expression to 
be stagnant and instead can be thought of having the capacity of fluid movement between the two poles.

\section{Postfeminism}

Postfeminism is yet another contested point of feminism, largely because it is used as a broad descriptor and has no agreed upon definition (Lumby, 2014). The term, postfeminist, was originally used to describe a backlash against feminisms emerging in the 1980s (Kearney, 2012). Some scholars classify it as "anti-feminism" (Kinser, 2004; McRobbie, 2007; Modleski, 1991) whereas others see it in a, somewhat, more positive light as a necessary critique of feminism (Le Masurier, 2011; Lumby, 2014). Modleski (1991) finds that postfeminist media, rather than critiquing feminism, instead actively negate and undermine feminisms' goals. An inherent difficulty of postfeminism's contested meaning is that it makes it difficult to locate specific features which, in turn, prevents analysis (Gill, 2012).

As a plurality of feminisms exist, so too do a plurality of postfeminisms. First, postfeminism is equated roughly with the third-wave of feminism and represents a generational divide between the second- and third-waves of feminism (Kearnery, 2012).

Second, postfeminism is portrayed as a backlash against feminism which often corresponds to the decrease of overt sexism of the $21^{\text {st }}$ century where many women do not feel as disadvantaged by patriarchal forces (McRobbie, 2007). As Kinser (2004) states, postfeminism "co-opts the motivating discourse of feminism but accepts a sense of empowerment as a substitute for the work toward and evidence of authentic empowerment" (p. 134). Finally, a more nuanced and neutral position is taken by Lumby 
(2014) who deems postfeminism "a set of discourses that move back and forth between the popular and the scholarly" (p. 602) where feminisms can be more critical examined. Taking a similar perspective, Le Masurier (2011) sees postfeminism as a cultural space where discourse on feminism can take place, acting as more than just a representation of academic feminism in popular media.

Another point of contention within the third-wave feminism and postfeminism movement is their relationship with popular. According to Kearney (2012), third-wave feminism recognizes popular culture as a "dominant site where feminism is constructed and negotiated" (p. 7). Third-wave feminism's interaction with popular culture has resulted in confusion over whether it can be equated to postfeminism. Acknowledging the struggle of third-wave feminists to set themselves apart from second-wave feminists, Kinser (2004) suggests instead that it is imperative for the third-wave to distinguish itself from postfeminism.

The result of third-wave feminism's departure from the second-wave's more singular definition combined with the third wave's embracement of multivocality and intersectionality is a multitude of feminisms. Given the existence of a plurality of feminisms, it stands that a place exists for discourse to occur in order to aide in the understanding and construction of their meanings. The narrative approach of third-wave feminism allows for women to explore what it means to "do" feminism (Kinser, 2004). However, in doing so the narrative discourse on feminism has become intertwined with postfeminist narratives. 


\section{Men and Feminism}

Do men have a place in feminism? This is a question that does not yield an obvious answer, at least when consulting more popular forms of feminism found in the media. To answer this question, one must have delved into feminist thought and explored the numerous feminist perspectives that exist. According to hooks (2000b), the rhetoric of men as repressors and women as victims created by liberal feminists "reinforced sexist ideology by positing in an inverted form the notion of a basic conflict between the sexes, the implication being that the empowerment of women would necessarily be at the expense of men" (p. 83). However, current feminist thinking has advanced as the movement has progressed to understand the problem as "patriarchy, sexism, and male domination" which is not just the fault of men, but jointly maintained and perpetuated by both sexes (hooks, 2000a). Others argue that given feminism's diverse approaches, there is nothing intrinsic that "necessitates the exclusion of men" (Herbert, 2007, p. 35). Regardless, once men are separated from a "unidimensional conceptualization of masculinity" (Herbert, 2007, p. 38), a totalizing approach to patriarchy is flawed "for this is not the rule of all men over all women on the basis of their sex alone; it rather involves multi-layered hierarchies, in which gender, race, sexuality, class, and other factors mix in a relatively fluid process" (Hooper, 2001, p. 72). Feminism as a movement is inclusive; it is about taking action that benefits all groups affected by hegemonic power (Tarrant, 2009). Restricting feminism to women alone would be in direct conflict with the movement's inclusive goals. 
Feminism benefits from men's inclusion and participation in the movement, as their involvement in efforts towards gender justice "maximizes the potential for deep, sustained social change" (Tarrant, 2009, p. 17). Previous separatist ideology conveyed the belief that women alone could manifest a feminism revolution, but since sexism and sexist oppression are maintained and supported by men "they can only be successfully eradicated if men are compelled to assume responsibility for transforming their consciousness and the consciousness of society as a whole" (hooks, 2000b, p. 83). As Herbert (2007) attests, "women acting alone are not enough to oppose the momentum of the prevailing social arrangement or to galvanize a critical mass of society willing to adopt new behaviors and interactions" (p. 41); doing so will require the partnership of men in order to achieve the goals of feminism. Men have the potential to greatly contribute to feminism as a movement by "exposing, confronting, opposing, and transforming the sexism of their male peers" (hooks, 2000b, p. 83). This is especially true when considering that many arenas still exist in which men's voices are privileged over women's (Tarrant, 2009). Similarly, anti-male sentiments have harmed the feminist movement by alienating women of color and/or lower socio-economic status as their experiences hold more in common with men who share similar identities rather than upper-class white women (hooks, 2000b). A feminist movement that is seen to be more inclusive to men also serves to present a movement that more closely aligns with women hesitant to align themselves with feminism.

What may be less apparent about feminism is that men also stand to benefit from the movement. Herbert (2007) claims that feminisms' goals are in the self-interest of 
men, because men benefit from combined efforts to remove forces of subordination. It is important to note that the "patriarchy does not negate the existence of class and race privilege or exploitation;" thus not all men benefit equally from it (hooks, 2000b, p. 69). While men are not victims of sexism, they are confined to socially acceptable expressions of male gender identity; primarily through the imposition of hegemonic masculinity (hooks, 2000a; 2000b, Kimmel, 2005). According to Kimmel (2005), men feel intense pressure to prove their masculinity and as such operate in a "defensive effort to prevent being emasculated" (p. 39). Because the definition of masculinity is set in opposition to femininity, men perform exaggerated masculinity against women and gay men, the perceived "others," in order to prevent emasculation (Kimmel, 2005). Men perceive a need to continually prove their masculinity, which requires that they avoid performing in ways socially coded as feminine and prevents them from feeling that they can express a full range of emotion (Kimmel, 2005). Studies focusing on men's health have found that hegemonic masculinity has a negative impact on men's health (Cohn et al., 2010; Courtenay, 2000). However, feminism has been hampered in that it has yet to provide what men can do to be anti-sexist as well as what might constitute alternative masculinities (hooks, 2000a). Herbert (2007) also critiques this absence in feminism, stating that "men's relationship to feminism has largely been limited to object status -essentially the 'problem to be solved', as opposed to being acknowledged as role players in the transformation of masculinism" (p. 35). 


\section{Social Identity Theory}

In order to explore men's relationship with feminism and whether or not men feel able to identify as a feminist, social identity theory (SIT) provides insight into how individuals determine their social identity and membership in groups. SIT describes the process of social categorization, which provides insight on how individuals come to identify themselves as part of a group, such as feminism. SIT also provides guidance on how individuals construct concepts of who belongs to a group, which provides insight as to whether men can evaluate themselves as being able to identify as part of a feminist movement. As such, SIT was used to help formulate the research questions for this study and will help to address how multiple group memberships are managed by individuals.

Social identity theory (SIT) originates from the work of Tajfel whose interest in a cognitive theory of stereotyping led him to use laboratory settings to explore social mental processes (Hogg \& Williams, 2000). Tajfel's goal was to expand the explanation of intergroup phenomena beyond the "expression of personality traits, individual differences, and interpersonal processes" which stood in opposition to the dominant paradigm at the time (Hogg, 2006). Hogg (2006) outlines four areas of research conducted by Tajfel which led to SIT: first, studies which explored the effects of categorization on people's attention to similarities and differences between different categories; second, analyses of categorization in instances of prejudice; third, group favoritism as affected by categorization; and finally, Tajfel's critique of social comparison research where he argued that differences are maximized in comparisons made between in-group and outgroup members. 
Tajfel and Turner (1979) stated that SIT integrates "the three processes of social categorization, self-evaluation through social identity, and intergroup social comparison, into a coherent and testable framework for contributing to the explanation of various forms of intergroup behavior, social conflict, and social change" (p. 46). As such, SIT includes analysis of social categorization, motivation, and cohesion, rather than just "the analysis of intergroup relations and social change as a function of positive distinctiveness" (Hogg, 2006, p. 11). SIT focuses on group situations operating under the assumptions that social identity results from group membership (Brown, 2000).

\section{Social Identity}

Tajfel (1972) first defined social identity as "the individual's knowledge that he belongs to certain social groups together with some emotional and value significance to him of this group membership" (p. 292) which shows how an individual creates and defines their place in society through their group membership. Social identity, according to Tajfel and Turner (1979), is composed of the parts of an individual's self-image that are formed based on the social categories that the individual perceives membership in.

When an individual is aware of their social identity, the "group prototype is the basis of perception, inference, and behavior" (Hogg, 2006, p. 121). A prototype is a vague set of attributes (behaviors, attitudes, beliefs, etc.) that are meaningfully related while simultaneously encompassing similarities between group members as well as differences between the collective in-group and out-groups (Hogg, 2006). In SIT, the prototype is the cognitive representation of a group or category that allows for differentiation to be established between in-group and outgroup members. Prototypes are 
an approximation of the ideal in-group member, as they are polarized away from the characterization of outgroup members rather than a description of the average group member (Hogg, 2006). Since the prototype describes the ideal group member, it prescribes the behavior for membership within the group. Depersonalization is the viewing of someone according to the attributes of that group, depending on the perception of the attributes the resulting opinion can be positive or negative.

Categorization of someone as part of the group transforms how you view them because of the comparison, and consequential depersonalization, against the group prototype (Hogg, 2006).

An individual's awareness of social identity as part of their definition of self is dependent on the function of five factors which Hogg and Williams (2000) define as:

(a) individual motive for self-enhancement (self-esteem) or self-evaluation (uncertainty reduction), (b) the contextual accessibility of specific social categorizations, (c) the accessibility of specific social categorizations in memory, (d) how well a specific categorization accounts for relevant similarities and differences among people (structural or comparative fit), and (e) how well a specific categorization accounts for others' actual behavior (normative fit). (p. 89)

According to Hogg (2006), four types of social identity exist: first, person-based social identities which place emphasis on the part of the self-concept that is based on the internalized properties of groups by individual members; second, relational social identities are those where the self is defined in relation to others within group situations; third, group-based social identities which aligns with Tajfel's (1979) definition; and, finally, collective identities where group members "engage in social action to forge an image of what the group stands for and how it is represented and viewed by others" (Hogg, 2006, p. 116) instead of just sharing self-defining attributes. 
Tajfel and Turner (1979) operated with the assumptions that, first, individuals strive to maintain a positive self-concept and, second, that social groups have a positive or negative value which influences the social identity of individual members. A third assumption made by Tajfel and Turner (1979) is that people evaluate their own group through comparison of value-laden attributes and characteristics of specific other groups. Using these general assumptions, Tajfel and Turner (1979) define the theoretical principles of SIT as (1) individuals work to establish and sustain a positive social identity, (2) positive social identity is largely dependent on favorable comparisons made between the in-group and a relevant out-group, and (3) individuals will attempt to alter their group membership by leaving and joining a more positively perceived one and/or increase the prestige of their existing group when their social identity is unsatisfactory.

\section{Group Identification}

Tajfel and Turner (1979) conceptualized a group "as a collection of individuals who perceive themselves to be members of the same social category, share some emotional involvement in this common definition of themselves, and achieve some degree of social consensus about the evaluation of their group and of their membership of it" (p. 40). Fundamental criteria for group membership is that individuals both define themselves and are defined by others as members of a group (Tajfel \& Turner, 1979). In other words, it is essential that individuals are identifiable and identify with the collective group identity. Interpersonal interactions with other group members are less significant in establishing group identification. According to Tajfel and Turner (1979), there are three variables which should have influence on intergroup differentiation. The first of these is 
that being defined by others as part of a group alone is not enough; the internalization of group membership as part of an individual's self-concept is necessary (Tajfel \& Turner, 1979). Second, the social environment must permit that intergroup comparisons be made that enable individuals to select and evaluate relevant relational attributes (Tajfel \& Turner, 1979). Finally, there must be a relevant group to use as comparison, thus establishing the outgroup (Tajfel \& Turner, 1979).

\section{Identifying as a Feminist}

Studies exploring the degree to which people, primarily women, were willing to adopt the feminist label found that, despite holding feminist ideologies, the majority were reluctant to self-identify as feminists (Anderson, 2009; Burns, Aboud, \& Moyles, 2000; Buschman \& Lenart, 1996; Jackson, Fleury, \& Lewandowski, 1996; McCabe, 2005; Twenge \& Zucker, 1999; Williams \& Wittig, 1997; Zucker, 2004). The unwillingness to adopt a feminist label makes sense given the negative connotation held by the term feminist (Buschman \& Lenart, 1996; Toller, Suter, \& Trutman, 2004; Williams \& Wittig, 1997; Zucker, 2004). The combination of these factors has led to a distinction to be made between feminist attitudes and feminist identity as two separate concepts, despite previously being used interchangeably (Cowan, Mestlin, \& Masek, 1992; Eisele \& Stake, 2008; Szymanski, 2004). This is important because self-identification as feminist corresponds to an increase in the likelihood of women's participation in feminism or feminist forms of collective action more so than those who hold feminist attitudes but disavow the feminist label (Eisele \& Stake, 2008; Fitz, Zucker, \& Bay-Cheng, 2012; 
Kelly \& Breinlinger, 1995; Liss, Crawford, \& Popp, 2004; Williams \& Wittig, 1997, Zucker, 2004; Zucker \& Bay-Cheng, 2010).

Women accept the feminist label to a greater degree than men (Breen \& Karpinski, 2008; Williams \& Wittig, 1997), although studies have shown that there are men who professed liberal feminist attitudes while rejecting the label feminist (Breen \& Karpinski, 2008). Williams and Wittig's (1997) survey of college students found that over half of participants supported feminist goals while not identifying as feminists, whereas a quarter of their respondents identified as feminists. Overall, women used the feminist label more than men (Williams \& Wittig, 1997). In Williams and Wittig's (1997) research, they found that men had lower scores than women on "support of feminist goals, exposure to feminism, positive evaluation of feminists, and belief in collective action" which were the four variables used to predict feminist identification. In a study conducted by Breen and Karpinski (2008), students of a Northeastern college participated in a survey where they gave their impression of a vignette that was manipulated for gender and feminist identity. Breen and Karpinski (2008) found that men endorsed liberal feminist attitudes but disavowed the feminist label, while women held stronger liberal feminist attitudes and were neutral in feminist identification. The perception that feminism as a movement is reserved for women and that it is not appropriate for a man to be a feminist were posited as reasons for this discrepancy (Breen \& Karpinski, 2008).

Researchers studying identification with the label of feminist have established that the label often lies in conflict with masculine identities (Breen \& Karpinski, 2008; Toller, 
Suter, \& Trautman, 2004; Suter \& Toller, 2006). Toller and colleagues (2004) found that "highly masculine men were less likely to consider themselves feminists" (p. 88). Another aspect that presents a challenge to men identifying as feminist is that they understand their gendered behavior as normal. According to Martin (2001), due to how “men’s practices (re)producing gender inequality are heavily embedded in social, economic and cultural relations" (as cited in Holmgren \& Hearn, 2009, p. 404), their behavior has been accepted as normative behavior and is not commonly understood, especially by men, to be gendered.

According to hooks (2000b) women have established the feminist movement as "women's work" through equating the movement with women reaching social equality with men, thus establishing the movement as exclusive to women. Studies exploring men's identification with the feminist label posit that feminism remains coded female and that the term feminist still invokes images of women and not men (Anderson, 2009; Breen \& Karpinski, 2008; Toller et al., 2004; Suter \& Toller, 2006; Williams \& Wittig, 1997). Breen and Karpinski (2008) found that despite agreeing with feminism principles, the perception of feminism as a movement that only includes women contributes to men's disinclination to identify as feminist. Similarly, Herbert (2007) argued that because feminism privileges the 'lived experience of 'women' in feminisms, men who align themselves with feminism or claim the identity 'feminist' often encounter suspicion, outright hostility, or the attempt by (female) feminists to distance them from this identity." (p. 39). However, according to Holmgren and Hearn (2009) "breaking norms of masculinity as a bodily practice can self-verify (pro)feminist position" (p. 411). 
Wiley and colleagues (2012) found support for the argument that when a feminist identity is construed as inclusive of their own self-views, more people may be willing to identify as feminists. Toller, Suter, and Trautman (2004) argue that in order to increase men's support of feminism, "feminists should emphasize definitions that do not view support for feminism as inconsistent with a masculine identity" (p. 89). Such an approach is problematic because it would continue to promote the idea that femininity is inherently incompatible with masculinity. Recognizing that feminism would be caught in a difficult rhetorical position by placing emphasis on both feminine and masculine definitions of feminism, Toller, Suter, and Trutman (2004) suggest that feminism should construct gender neutral definitions. However, it is not apparent how a more gender-neutral definition of feminism would be able to combat the existing female connotation of feminism (Anderson, 2009; Holmgren \& Hearn, 2009; McCabe, 2009). Thus, the issue of female connotation of feminism persists as an issue if feminist identification does stand as "the link between positive portrayals of feminist men and men's collective action in support of women" (Wiley et al., 2012, p. 62).

In a series of interviews with men in Sweden conducted in order to better understand men's experiences with feminism, Holmgren and Hearn (2009) found that the presiding perspective was that it is easy for men to enter a feminist space merely by espousing feminist beliefs. Claiming a feminist perspective was enough for men to be able to enter feminist spaces, but it was not necessary for these men to prove their feminist stance through their actions. Holmgren and Hearn (2009) stated the opinion that men's participation is crucial, but their study suggests that participation is a more 
complicated and multidimensional issue. Essentially, because of their position as men, merely through the expression of feminist beliefs, men are given credit for participating in feminism without having to prove their alignment with feminism through actual practice. This bares the question of whether men define a feminist identity as the articulation of feminist views or through active participation in feminism.

In their analysis of these groups, Holmgren and Hearn (2009) discerned that identifying as both a man and a feminist "seems to make issues of one's own subject position ambivalent and contradictory" and acknowledge that "passing as a (pro)feminist man requires being acknowledged as one by others, yet at the same time expecting to be defined as the problem to be solved" (p. 412). It is interesting to note that in Holmgren and Hearn's (2009) analysis, they do not make a distinction between pro-feminist and feminist identification. Failure to distinguish between support of and identification with feminism ignores the importance of the distinction between terms. Identification as a profeminist man carries the understanding that men are not allowed to directly be part of the feminism movement, thus preserving the conceptualization that feminism is only for women.

If feminism is instead to be understood to inclusive movement against hegemonic forces of oppression which understands gender to be socially constructed and exist along a spectrum, then it is important that men be able to identify themselves with the feminist label. The importance of men being able to identify as directly part of the feminism movement, rather than just an ally in support of it, is the difference in the likelihood of their active participation in the movement (Zucker \& Bay-Cheng, 2010). Zucker (2004) 
found that making a distinction between feminists, egalitarians (e.g., pro-feminists), and nonfeminists allowed for a more accurate prediction of different kinds of behavior, where self-labeled feminists would be more likely to take public action in support of women's rights.

Having established that current understandings of feminism do not seek to dissuade men from feminism as a movement, men's inclusion is seen as paramount to achieving equality between women and men, a common goal among feminisms. Despite this, research on feminist identity rarely includes men, and instead focuses on women's identification with the feminist identity. The feminism research that does include men as participants fails to fully explore whether men feel able to adopt a feminist identity.

Given the limited amount of research on men's identification with feminism and that that identifying with a movement indicates a greater likelihood of participation, it is important to delve deeper into what men understand feminism to be and whether they feel able to identify as feminists.

In order to explore how men engage with feminisms, it is first necessary to interrogate men's perception of feminisms. As multiple understandings of feminism exist and dialogues on feminisms take place in multiple spheres, my first research question seeks to explore the definitions and understandings of feminism that men utilize in their own lives. Exploring my participants' definitions of feminisms allows me to ascertain feminist prototypes utilized by men. Since prototypes are an important feature of SIT of group identification and differentiation, it is salient to ascertain the answers to this research question: 


\section{RQ1: How do men define feminism?}

Feminisms being understood as feminine, which perpetuates the perception of an exclusively women's movement, presents a potential challenge to men identifying as feminists or participating in feminism. The importance of self-identification with a movement in order to increase active participation necessitates further investigation of men's identification with feminism and prompts a second research question.

RQ2: What do men feel their role is in feminism? 


\section{Chapter 3: Methods}

This study uses focus groups because they provide the opportunity to see discourse in action. Observing discourse as it is produced facilitates the use of SIT and a social constructionist framework to learn more about self-identification in social settings. Focus groups provide the unique ability to see group interaction between members of a specific population segment as well as to provide insight into the individual. The use of focus groups is preferable over that of individual interviews or surveys because "the hallmark of focus groups is the explicit use of the group interaction to produce data and insights that would be less accessible without the interaction found in a group" (Morgan, 1988, p. 12, original emphasis). The ability to see group dynamics in action helps to expose how social identity is constructed and managed, specifically between identification with two, potentially conflicting, identities: male gender and feminist.

Observation and analysis of conversations between male gendered participants will allow for observations of "collectively shared discursive constructions of feminism which make up the social contexts in which feminism is negotiated in private and public arenas" (Edley \& Wetherell, 2001). In this sense, focus groups allow for observation of the "individual in social context" which is important for the navigation of an individual's social identity (Rubin \& Rubin, 1995, p. 95). Focus groups allow for the observance of “ordinary social processes and everyday social interchange" (Wilkinson, 1998, p. 120). An added benefit of observing a group is that groups provide individuals the opportunity to make connections to concepts through discussion that would not have occurred during 
a one-on-one interview. Another advantage is that focus groups allow the researcher to follow up on emergent themes and information that were not anticipated.

\section{Participants}

Participants consisted of 17 male-identified undergraduate communication students from a research university in the U.S. Pacific Northwest. Of the participants, $58.8 \%$ identified as Caucasian, $23.5 \%$ as Asian, and $17.6 \%$ as Hispanic. Students were recruited via undergraduate communication courses and offered extra credit for their participation. If a student chose not to participate or was not selected for a focus group, I provided an alternative assignment for extra credit of equal value. Participants were selected based on their male gender identification, age, and their availability to attend one of the scheduled focus group sessions. Only male gender identifying individuals were selected for this study for two reasons. First is the limited amount of research on male identification with feminism(s) (Anderson, 2009; Breen \& Karpinski, 2008; McCabe, 2005; Pierce et al., 2003). Second, the focus on feminism, a gendered and potentially controversial topic, would possibly make it difficult to elicit as open response in mixed gender focus groups (Stewart, Shamdasani, \& Rook, 2007). As this study focuses on SIT and individual identification with groups, it is important that those who identify as male, regardless of their biological sex, be selected as participants (Butler, 1988; Lorber, 1994).

This study's definition of male includes all individuals who have the gender identity of male in order to respect the diversity of lived experiences of those who share the male gender identity. Such a broadly defined category attempts both to capture the wide range of experiences that fall within the category of male while avoiding the 
limitations imposed by using biological sex. As current iterations of feminist thought have come to understand a singular category of woman as problematic, so too is the conceptualization of a singular category of man, as it similarly fails to capture the diversity of lived experience (Herbert, 2007).

All of the participants were between the ages of 21 and 36, with a mean age of 26 $(S D=5.18)$. Participants were required to be over eighteen and fall within the age range for millennials as defined by this study. The Pew Research Center (2015) defines millennials as born between 1981 and 1997, but states that there is no chronological end point that has been set for this age group. As such, this study considered those born the year 1981 and after who are eighteen or older at the time of this study as Millennials in order to clearly define an age group. Age restrictions were set for this study because of changing attitudes around feminism in the last forty years and the ability to more clearly define the group that is being examined. The aim of the limitation is to provide a more detailed understanding of male-gendered individuals and their experience with feminism. By defining a generation age set, the study aims to decrease generational differences in the target group of study and to increase the homogeneity among focus group members as this "allows for more free-flowing conversations among participants within groups" (Morgan, 1997, p. 8).

\section{Procedure}

Students were recruited for focus groups via undergraduate communication courses. The researcher made in-person announcements in these courses using a prewritten recruitment script (Appendix A). The decision was actively made to use "men" in 
the recruitment script because that is the desired demographic of the study and hopefully, individuals who are male gender identified would understand that designation to include them. Additionally, using alternative language could potentially give the impression that an aspect of the research project is on different gender identities which could prove alienating to those less open to the idea of non-cisgender identities and persons who do not wish to disclose details about their gender identity. This study aimed to include a variety of masculine identities and perspectives which could be impeded by the use of "male gender identified" as it could dissuade those who do not support trans individuals from participating in the study. Gender identity is an important aspect of this project, the focus of the research is specifically on male identification with feminism(s) and, aside from gender identity on the pre-survey screening, personal disclosure of sex and gender was not required of participants during the focus groups.

Students interested in participating in the study were given the link to an online pre-screening survey using Qualtrics. The pre-screening survey directed students who met the selection criteria to indicate their availability to partake in a focus group session along with their name and email address so they could be contacted regarding scheduling (Appendix B). Students who did not meet the selection criteria were directed to an alternative assignment worth an equal amount of extra credit as participation in the focus groups. The pre-screening survey was also used to assess participants' existing selfidentification with feminism. In order to avoid priming participants to the study's focus on feminism, participants were asked to indicate whether they identified with a variety of social movement labels in addition to feminist in order to disguise the focus of the study. 
The order in which the social issues and identities were presented was randomized using Qualtrics. Participants were also asked to indicate their level of support for feminism, as well as a number of other social issues, to disguise the focus of the study.

Three focus groups, the first and third of which had six participants and the second with five participants, were held in a room designed for research. Participants and the moderator sat in a circle as a group in order to encourage as much conversation as possible. The focus groups were conducted using a semi-structured approach in order to elicit issues and information that was unanticipated by the researcher. The moderator's guide employed a funnel technique. This required starting with broad questions about feminism in general to increasingly more specific questions about men and their relationship with feminism (Appendix C). Broad questions were used at the start of the moderator's guide in order to elicit men's understandings of feminisms and feminist qualities. As the moderator's guide went on, increasingly specific questions that aimed to prompt conversation surrounding perceptions of feminists, whether or not men can be feminists, and perceptions of male feminists were used. The majority of questions posed in the moderator's guide included probe questions to further elicit discussion as necessary. This was done in order to provide enough data to ensure that each research question was thoroughly addressed.

The funnel design is an essential technique for researchers to use because it allows them to learn from the group. Starting broadly allows the group to contribute their views and de-centers the moderator as the expert and group leader. This creates space for open conversation flow and starting with minimal moderator input allows the group to 
establish discussion between themselves rather than with the moderator as focal point (Morgan, 1997). Additionally, it is the purpose of this study to see how the group members construct identity prototypes, as well as their definitions of feminism(s), through discourse. In conjunction with minimal moderator involvement, each focus group started with the moderator moving back from the circle in order to establish each focus group as a conversation among its members. Moving back from the circle also discouraged the perception of the moderator as the conversation leader. This also contributed to the effort to prevent myself, as a female moderator, being seen as expert on the topic given the study's focus on feminism.

While a semi-structured approach was used, the goal of the study was to elicit as natural, casual conversation as possible from the participants. As such, participants were encouraged to speak when they wanted to contribute, not just when prompted to do so, and to interact directly with one another without being told to do so by the moderator. Follow up questions were used by the moderator to gain further elaboration, explanation, or clarification on points made by participants during the focus group sessions. Questions used to follow up on points made by participants included "Could you explain your point in more detail? What do the rest of you think about that perspective? Could you be more specific?” Each focus group session lasted approximately 90 minutes.

Before the start of each focus group, participants were checked in, allowed to review and sign consent forms, and were assigned pseudonyms for the study. Once participants were checked in and situated in the room, the moderator read through the beginning of the moderator's guide outlining the expectations for conducting the focus 
group (Appendix C). After establishing the format, the moderator elicited verbal consent to audio and video recording and participation in the study from each individual present before proceeding.

\section{Analysis}

A thematic analysis allows for "a purely qualitative, detailed, and nuanced account of data" (Braun \& Clarke, 2006, p. 400) which works to "arrive at an understanding of a particular phenomenon from the perspective of those experiencing it" (Vaismoradi, Turunen, \& Bondas, 2013, p. 398). Per Braun and Clarke’s (2006) guidelines for conducting thematic analysis, I chose to do a thematic analysis of the focus groups to provide a rich overall description of the data set due to the limited research of men's views on and participation in feminisms. Due to the amount of time that has passed since previous studies on men's relationship with feminisms as well as the limited number of participants in these studies, I analyzed the focus group transcripts inductively (Vaismoradi, Turunen, \& Bondas, 2013).

Focus group data from each group were transcribed verbatim and used in their entirety to construct the data set. I used a primarily inductive approach to establish themes that are strongly linked to participants utterances. Some deductive analysis in establishing themes was unavoidable due to the influence of conducting a review of the literature in advance, the semi-structured approach of the moderator's guide, which was informed by the literature review, and desire to directly address the specific research questions set forth at the beginning of this study. As a result, my interpretation of participants' utterances was partially influenced by my advance research. Additionally, as 
the data set is composed of focus groups where participants responded to specific questions which were informed by a review of the literature and designed to illicit responses corresponding to pre-established research questions, it stands that a more inductive approach would illicit themes that correspond more directly to specific research questions (Braun \& Clarke, 2006).

Given the literature I reviewed and used to construct the moderator's guide, "men's definitions of feminism," "definitions of feminism," and "goals of feminism" were used to initially group sentence level data in order to allow inductive codes to emerge. Additionally, SIT informed establishing "feminist prototypes" and "perception of feminist men" as broad initial groupings. Lastly, the existing literature on men identifying as feminist inspired the construction of "men participating in feminism," "impact of feminism on men," "how participants learned about feminism," and "feminist belonging" as initial groups. I then coded the thematically grouped focus group transcripts at the sentence level working to use codes as close as possible to the participants' utterances. These codes were then grouped together to establish themes. Multiple readings of the transcripts allowed for codes and themes to emerge from the data. After coding the transcripts, individual codes were grouped together into categories so that overarching themes might be made apparent. Refinement and reiteration of code grouping saw that codes were assigned only to the group they best fit (Vaismoradi, Jones, Turunen, \& Snelgrove, 2015). Prevalence of a theme was considered by the number of participants expressing a theme in conjunction with how often that theme occurred in 
separate utterances as instances of a theme across the data set do not necessarily correspond to the level of importance (Braun \& Clarke, 2006).

Four major themes were identified through analyzing participant discussions across three focus groups at the sentence unit level: taking action; feminism as women only; feminist aggression; and men's contributions to feminism. An additional two emergent themes manifest through this analysis: men's equal-ist stance and feminism through relationships with women. Below, the total number of of sentence units drawn from each focus group that makes up a theme is going to be explicated with the hopes of illustrating general patterns of how a theme was constructed from and discussed by participants across focus groups within this study. It should be noted these are merely counts and further nuance and analysis regarding each theme are further discussed within the results section.

Four major themes emerged from analyzing participants' discussions across three focus groups. First, a total number of 65 sentence-units drawn from three focus groups make up the feminism as women only. Of these 65 sentence-units, 10 sentence-units were found in focus group one, 45 sentence-units were found in focus group two, and 10 sentence-units were found in focus group three. Second, the taking action theme was comprised of 44 sentence-units from three focus groups. Of these 44 sentence-units, 21 sentence-units were found in focus group one, 10 sentence-units were found in focus group two, and 13 sentence-units were found in group three. Third, the feminist aggression theme was comprised of 17 sentence-units across all three focus groups. Of these 17 sentence-units, zero sentence-units came were found in focus group one, nine 
sentence-units were found in focus group two, and eight sentence-units were found in focus group three. Lastly, the men's contributions to feminism theme was comprised of 69 sentence-units. Of these 69 units, 30 sentence-units were found in focus group one, 21 sentence-units were found in focus group two, and 18 sentence-units in focus group three.

Two emergent themes were identified from analyzing participants' discussions across three focus groups. First, feminism through relationship with women comprised of 20 sentence-units. Of these 20 sentence-units, seven sentence-units were found in focus group one, 10 sentence-units were found in focus group two, and three were found in focus group three. Next, the equal-ist theme comprised of 17 sentence-units. Of these 17 sentence-units, four sentence-units were found in focus group one, five sentence-units were found in focus group two, and eight sentence units were found in focus group three.

These counts are present to reflect on the methodological process of establishing themes. While the quantification of qualitative data can provide some insights, it can also serve to obscure the expressed perspectives of participants by removing nuance (Hannah \& Lautsch, 2011). It should be noted that the very process of counting erases "the inherently qualitative nature of all data conversions as they necessarily entail researchers' judgments about what will constitute data and how to represent them" (Sandelowski, Voils, \& Knafl, 2009). Additionally, the use of numbers to represent qualitative findings can run the risk of delegitimizing insights gained from less prominent qualitative data points (Pratt, 2008). The nuance of the qualitative data that comprise these themes is explored and analyzed within the results section of this study. 
Operating under the social constructivist paradigm required repeated iterations and analysis of the data to allow for the emergence of the construction of multiple understandings of feminisms as well as the various ways in which participants identified with those feminisms. In evaluating the focus group transcripts, interactions and dialogue between the participants were considered in order to evaluate how members of the group responded to one another. Additionally, pre-screening surveys were matched to focus group participants in order to better inform on individual demographics, social identities, and ideologies.

A significant aspect of the focus group conversations was centered around identifying as feminist. This topic was discussed by participants with regard to both their personal perspective on adopting a feminist identity as well as their perception of other people's identities. Participants also discussed how they viewed people who proclaimed a feminist identity. While some participants expressed their perception that feminism has become more expansive and that a feminist identity is not dependent on gender identity, other participants in the focus groups specifically expressed not feeling able to relate to feminism because of their gender identity. Some participants navigated their ability to identify and be identified as a feminist through describing their political identity as equalist. An "equal-ist" identity emerged as a theme through inductively coding participants responses. This section aims to demonstrate how this theme emerged through explicating the coding process.

The "equal-ist" theme emerged from a group of codes that did not readily fit into a family based on either research question, instead was a collection of sentences that 
expressed identification with a broad sense of equality over a feminist identity. After grouping codes into families, each family was re-grouped into common themes within each family. Thus, the family acted as an umbrella unifying a number of related but distinct themes. The "equal-ist" family proved to be one, unified theme of sentiment expressed by a number of different participants across focus groups. A total number of 17 unique sentences from across focus groups were coded as part of the "equal-ist" theme. Utilizing four examples below, I illustrate how the "equal-ist" theme emerged and came to be defined through the coding process.

\section{Example 1:}

"For me, I would not say I am a feminist, I would say that I am trying to be an equal-ist." - Nick, Focus Group 1

After placing sentence within its family, it was coded as "equal" because the participant expressed identifying as "equal-ist" over being a feminist. This sentence illustrates a sentiment that participants across all focus groups expressed, specifically that they identify as an "equal-ist" opposed to just being a feminist. The participant is making a distinction between a feminist and "equal-ist" identity; however, it is not clear the exact nature of that distinction. Further analysis of sentences coded as "equal" helped to tease out the relationship between a feminist and "equal-ist" identity and further construct the "equal-ist" theme. The next examples illustrate how the "equal-ist" theme emerged and how participants' perceived the relationship between an "equal-ist" identity and feminist identity.

\section{Example 2:}

“So, I mean, if I was self-describing myself, I wouldn't say I'm a feminist, but I would say I am for equality for everyone, not just women, necessarily, but for everyone." - Warren, Focus Group 2 
This sentence was coded as "equal" because the participant described their political identity and values as promoting "equality for everyone," opposed to only promoting equality for women. The participant is possibly expressing that they do not label themselves as a feminist alone because they want equality for everyone. Feminism appears to be understood as promoting equality for women; however, participant also identifies with promoting equality for women and for everyone else. In this case, the "equal-ist" identity is encompassing of the participant's perceived intention of feminism, equality for women, while also striving to create equality for all groups. Overall, this sentence helps to illustrate that the "equal-ist" identity is perceived by the participant as more inclusive than feminism alone because it encompasses a greater range of identities. Simultaneously, it illustrates that the participant views an "equal-ist" stance as building upon feminism, not as an entirely ancillary political stance and identity. A feminist practice and participating in feminism can occur through taking up an "equal-ist" identity.

\section{Example 3:}

"But, if talking about feminism, then maybe equal-ism is a better way to say it because the word itself [feminism] has a certain stigma behind it." - Nick, Focus Group 1

The participant's use of equal-ism in this sentence prompted it be being coded as "equal" and used to further shape the emerging "equal-ist" theme. In this example, the participant expressed that "equal-ism" may be a better way to frame feminism because the stigma associated with feminism/feminist. The participant is possibly seeking to redefine feminism as "equal-ism", suggesting redefining feminism as such would avoid 
evoking negative stigma. This appears to suggest that the participant perceives an "equalist" stance and feminist stance as fundamentally aligned around creating equality. This example, along with others similar to it expressed across the focus groups, further shaped the emerging "equal-ist" theme by demonstrating how participants' possibly perceived the relationship between "equal-ist" and feminist stances. An "equal-ist" stance, again, is not opposed to a feminist stance; instead, it shares a perceived common goal of creating equality.

Example 4:

"Equality for everyone, rather than just one group needs to be higher." - Clyde, Focus Group 1

Here again is another example of a sentence coded as "equal." In this sentence it appeared that the participant expressed that equality for everyone is possibly a more meritable and just goal than promoting equality of one group over another. This is a central component of the "equal-ist" identity expressed by participants across the focus groups in this study. Again, this illustrates that participants' perceived an "equal-ist" identity and standpoint as being a more inclusive term than feminism, possibly because some of the participants expressed feeling that feminism did not encompass their identity. Put in conversation with other codes within the "equal-ist" family, the various perceptions about the extent to which participants felt they could participant in feminism and the variety of ways they defined feminism emerged.

This coding process helped illuminate how participants navigated contention over being able to take up and be recognized as a feminist and enact a feminist practice, which took the form of constructing an "equal-ist" or "equality for everyone" political stance. 
As is further examined in the results and discussion sections, the participants viewed the "equal-ist" stance as encompassing and being aligned with the goals of feminism.

However, the participants expressed that an "equal-ist" identity as being a more inclusive and accurate term for their political identity. An "equality for everyone" stance provided an inroad for the participants to take up a feminist practice and take up feminism, without labeling oneself as feminist. 


\section{Participants}

\section{Chapter 4: Results}

Based on the pre-screening survey's question of whether participants identified as feminist or not, ten (58.8\%) identified as feminist, six $(35.3 \%)$ did not, and one participant did not respond. Only one participant indicated that he had children (two daughters), while eight (47\%) participants had one or more sisters. Of the participants who had sisters, half had one sister and the other half had two sisters. As participants primarily chose to go by their own names within the focus groups, I use pseudonyms to refer to participants throughout this study.

In the first focus group, all six participants identified as feminist and five of the participants indicated that they were "strongly for" feminism while the remaining participant indicated moderate support. In the second focus group, two participants identified as feminist, two did not and the fifth chose not to respond to that survey question. Participants in this focus group had a range of support for feminism with one participant "strongly against" feminism, one participant who was "neither for or against" feminism, two participants who had moderate support, and one participant who had strong support for feminism. Finally, in the third focus group only two participants identified as feminists, while the other three participants did not identify as such. Reported support for feminism among the third focus group had three participants that were "strongly for" feminism, one "moderately for," and the remaining two participants indicating that they were "neither for or against" feminism.

Each wave of feminism has yielded new definitions of feminism and pushed the feminist movement to take up different political concerns and expand who can be 
considered a feminist. Popular conceptions of feminism and the feminist movement have reflected this process as well, albeit in its own way. Over the course of the last fifty years, definitions, goals, practices, and the boundaries of feminism and feminist practice have changed and been the subject of contentious academic and popular debate. The definition of feminism contributes to what issues the feminist movement politicizes, who is considered capable of being a feminist and having their values align with the feminist movement, what role different groups of people can take within the feminist movement, and how they perform and enact a feminist identity. Simply put, definition, practice, and identity are all interrelated. This was reflected in the results of the study. Participants' definitions of feminism were connected to how they understood their role within the movement and how they could, as men, enact a feminist practice. As such, focus group discussions on the participants' definitions of feminism often slipped into discussions of how they understood their own roles within feminism and how they could enact a feminist practice. Overall, focus group discussions on participants' definitions of feminism and how they understood men's role within feminism were interrelated and were discussed simultaneously. This may not be a surprise, given that many of the participants felt that men needed enact a feminist practice in order to be considered a feminist or at least stand up for feminist principles. Thus, definition and practice were interrelated for participants. This is overlap in conversation topic is reflected in the results. 


\section{Men's Definitions of Feminism}

The first research question sought to explore the definitions of feminism held by participants. The discussion prompted by the moderator's guide and the participants' responses revealed a number of different vantage points outlining feminism(s). There were two key findings from exploring how male participants defined feminism(s): 1) feelings of inclusion in feminism, as expressed by participants, existed along a spectrum; 2) participants expressed taking action and enacting a feminist practice as an important aspect of identifying and being identified as a feminist. Prominent among the conversations was that feminism was understood to be expansive beyond merely women, instead incorporating a range of identities and issues under the mantel of feminism. While many participants expressed this, there were other participants who noted that this purported expansiveness did not extend to the point that they as men, particularly as white men, felt included. Further discussion among participants about feminism's focus on women's issues revealed that those that felt feminism was inclusive of men went on to express feeling located outside of feminism because of their gender. This indicates a potential disconnect among some participants between how they conceive the boundaries of feminism when directly questioned versus how they feel as an individual in relation to feminism.

According to a number of participants, taking action was an important aspect of identifying and being identified as a feminist. Participants asserted that a feminist practice needed to go beyond claiming a feminist identity to be considered a feminist. Failure to take action was seen by these participants as undermining a person's claimed 
feminist identity. Additionally, participants also noted that aggression was a trait commonly attributed to feminists. While this was noted by participants there was simultaneous discussion that this attribute was more of a negative stereotype of, particularly female, feminists that was likely a more uncommon trait of those who identify as feminists.

Identity was an important factor in the discussion on feminism by participants. Participants' own identities as well as the identities of those who participants perceived to be encompassed by feminism were pertinent throughout all three focus groups. A prominent topic for the first and second focus groups, which was less prevalent in the third focus group, was the idea that feminism was not just for women. Instead, these groups discussed how feminism has evolved to the point where more than just women stand to gain from the feminist movement. During a conversation among participants on how issues around transgender rights, immigration, and the economy are of concern to present day feminisms, Alex expressed his opinion that feminism is:

“... just continually evolving and it's just that, it's kind of just the equality of, it's extending to the point where it is just the equality of everybody. I think the stigma feminism gets is that 'women should be superior and women should be treated the same as men.' Where I think it's a little bit more complicated and it's not as black and white as people seem to make it out to be." - Alex, Focus Group 1

Alex had already voiced his belief that certain feminist issues, such as women's right to work, had been addressed, allowing for feminism to expand to other concerns facing those who identify as women. He also commented on the persistence of feminism's negative stigma, illuminating his view that this stigma originates from the perception that feminism works to position women as superior to men. 
In expressing that he saw feminism as concerned with more than just women's rights, Alex echoed a sentiment shared by over half the total participants that feminism is not specific to women and instead encompasses a more comprehensive litany of identities, including men. Participants in all three focus groups acknowledged that they did not see feminism as limited to women alone. Instead, they suggested that feminism aims to benefit a broader array of marginalized groups, including men. In the third focus group two participants readily agreed when another participant, Rob, stated "I don't think feminism, or being a feminist, is gender specific by any means."

Roughly a third of participants directly referenced feminism as not gendered female. Participants in the third focus group expressed the sentiment that a feminist identity was not restricted to women alone; however, this was more explicitly discussed in the first focus group. Part of the first focus group conversation concentrated on whether identifying as a woman made one a feminist, where some participants expressed the sentiment that a feminist identity is not restricted to women. The following quotation displays the sequence of exchanges between these participants in the first focus group:

Nick: “For me, feminism isn't based solely on gender. It's not that you have to be female to be a feminist. More so you have to protect the rights of a female if you're a male. It's not strictly based on gender. I think that it's more so about equality versus one sex getting... It's hard to define. Does anyone else feel that way or?"

Alex: "I agree. Yeah, I think it's extended and evolved more than just women's rights. I think it has evolved to include LGBT, racial, and almost like gender and gender-identity rights. It's evolved to the point where it's very inclusive. It just involves everything."

Russel: "Like having a mindset of equality for women is what feminism is and being a feminist is taking a step if you see an opportunity to make something equal or standup for somebody's rights. And I do think that uh, I don't want to say 
that the lines get blurred and that's how other classes get protected as well, but I think that the belief in women's rights and equality is what feminism is."

Nick first expresses that he views a feminist identity as resulting from protecting women's rights; this position is later expanded to a gender-neutral "somebody's" rights after the interjection from Alex about his view of feminism expanding beyond just women's rights. Even though Nick maintained he views feminism as a movement focused on expanding and protecting women's rights, he expressed the act of being a feminist in gender-neutral language. Often in the focus groups, participants voiced feminism as being about women's rights while maintaining simultaneously that feminism has expanded beyond just women's issues. One participant in particular captured the struggle between a desire for equality and an understanding of feminism as encompassing more than just a female identity.

'So, I just think it's interesting, at what point do women's issues just become people issues, you know?” - Aaron, Focus Group 2 Aaron's question poses a challenge to other participants' conceptualizations of feminism as only concerned with women's issues. Rather than accepting an expansion of feminism Aaron instead posits an expansion of women's issues, suggesting that women's issues might not be of concern to only women.

Conversely, there were a couple of participants that pushed back against the sentiment that feminism has expanded beyond women. Most notably, in the first focus group, a participant responded to a stretch of conversation about the inclusion of women in traditionally male-dominated professions resulting in the following exchange:

Russel: 'If feminism doesn't just cover women, if it's going to cover the LGBT community, if it's going to cover minorities, I mean, if it's going to be equality 
for all, it should be equality [participant's stress through increased volume] for all. We should not forget that there are men, that happen to be white."

Nick: "You're looking at a room full of them."

Russel: "Because that's, that really is, if we're really promoting women and minorities, what population is left that we did not cover? It's white men. I will say it, it's not comfortable, not what people want to talk about, but that's the reality that we live in."

Russel challenged other participants' view of the increased inclusivity of feminism, remarking that the increased inclusivity should not just apply to minorities. Interestingly, the participants holding the opinion of a more expansive feminism did not specifically note the inclusion of men. Russel's challenge to these participants was the first direct mention of men being included within a more expansive conceptualization of feminism. However, that Russel specifies "white men," possibly suggests he perceives non-white men as encompassed to a greater degree by feminism. Overall, there was little direct mention of race among participants aside from Russel, who repeatedly incorporated race, stating that "white males" specifically are not included in feminism.

Furthermore, participants in the second focus group made a number of remarks that expressed an inability to relate to feminism given their own identities as men.

"Like, there's certain aspects where I don't understand it [feminism] for sure... it's not in my bubble, it's not in my field, it's not in my realm" - Rick, Focus Group 2

Rick later reiterated his sentiment that feminism was outside of his "bubble," and further articulated that his male identity made him feel positioned outside of feminism. This directly contrasts discussion that occurred in the second focus group of feminism encompassing all identities, including men. The more extensive expression of feminism 
being exclusive to women among the second focus group was potentially due to the presence of two participants who were very vocal about their feelings of being excluded by feminism.

There was a substantial discussion, within all focus groups, of feminism's focus on helping women specifically, rather than a broader range of identities as previously discussed. Roughly half the participants in each focus group made some mention of feminism specifically acting on behalf of women. The majority of participants in each focus group discussed feminism as being about achieving equal rights and opportunity for women as well as reducing the barriers women face to doing so. The focus among these participants was on the equal treatment of women and their ability to have the same access as to their male counterparts. During the third focus group, the following exchange took place in response to being questioned about what participants felt were the goals of feminism:

Warren: "Just have women respected the same way as men. And just being able to do the same things men do without having extra judgement or any consequences leading up to it."

Rob: "Having the same opportunities, too. Being equal."

Steven: "Yeah, like equal pay and stuff like that."

Within this discussion, issues of specific concern to feminism were primarily economic in nature focusing on equal pay, the glass ceiling, and equal opportunity within the workforce. Briefly mentioned were reproductive rights and representation within the government. 
Within all three focus groups, discussions revolving around women's equality brought up cultural practices, specifically related to chivalry and dating. A number of participants expressed struggling with public perception of themselves when failing to meet social gender norms, such as letting a woman pay for a date. Still other participants saw a push for equality between sexes as an argument against traditional gender roles:

"Where does chivalry still fit in to our society if there's absolute equality? Maybe I want the door held open for me. Maybe I want to be treated like a real gentleman and have drinks bought for me. So, there's those cultural expectations that kind of get frustrating if we're going for complete equality, which I think, is the core value of feminism, or should be." - Chris, Focus Group 2

Chris expresses that he does not feel that women should hold dual expectations of equal treatment and traditional gender norms. This sentiment was also shared by other participants in other focus groups. This conversation progressed on to how men can be left out of conversations around rape and other issues commonly perceived as primarily women's.

A number of participants perceived that feminism, regarding issues affecting both genders, ignores men and neglects issues facing men specifically. This sentiment was especially prominent within the second focus group, which contained a greater number of participants who expressed more aversion to feminism than the other two groups, and, to a lesser degree, among members of the third focus group. Kevin, from the second focus group, was outspoken against feminism and identified as such on the pre-survey; he expressed that feminism makes him feel both "alienated" and "spoken against."

Despite this pushback, there were other participants who acknowledged that men may also benefit from changing expectations for women brought on by feminism: 
"Not like, so she has everything or she has all the chances that we [men] might have, but maybe we have the same chances that she has sort of thing. Does that make sense? So, if she has all the opportunities to go out and like explore all her interests, we [men] have the same opportunities that she has. Like, if she wants to be the breadwinner, then we [men] can be the stay-at-home dad." - Nick, Focus Group 1

Nick expressed a fairly common sentiment among participants, where benefits to men from feminism were largely seen as a side effect of women's increased equality. When directly questioned about how men might benefit from feminism, participants across focus groups cited the dissolution of gender stereotypes, and more equal treatment with regard to divorce settlements. Additionally, participants perceived that feminism benefits women in ways that would have a positive impact on men, primarily through decreasing the concern over the economic well-being of women and the safety of women.

Participants expressed that inclusion within feminism existed along a spectrum: some expressed feeling they could be included, others expressed feeling they could not because of their gender, while other participants expressed feeling doubly excluded because of their race and gender. Despite this expressed range of feeling included within feminism, participants, for the most part, saw themselves as able to act as feminists without adopting the identity label of feminist. Additionally, According to a number of participants, action was critical to establishing a feminist identity. In two of the focus groups, participants commented on individuals whose actions they perceived as contradicting a stated feminist identity:

"So, there's people who say they're feminists and they will just lay low and let whatever happens happen. But they have their opinion and they're not going to state it. But I think a feminist would be someone who actually goes and talks, like talks to them about it, being like 'This is not what's right. They deserve this, this 
and this. So, why are you treating them differently than you would want to be treated?"' - Ben, Focus Group 3

Participants contributing to these discussions acknowledged individuals who claimed to be feminists but whose actions failed to meet the participants' conceptualizations of feminist. In the process, participants critiqued the expression of a feminist identity without simultaneous action in support of feminism. Russel, a participant in the first focus group, questioned whether an individual's previous negative action towards women, deemed non-feminist by the participant, would be able to take on a feminist identity in the future. It should be noted that the individuals referenced by participants were seen as failing to enact behavior that fit with the participants' personally held understandings and definitions of feminism:

"I think people to a point can be very hypocritical when it comes to feminism. They will say that they are [feminists], they will promote it, but at the same point, they will, they have done things in the past that maybe weren't [feminist]."

- Russel, Focus Group 1

According to participants, failure to take action negates self-labeling as feminist. Thus, expressing a feminist identity was established as not enough to legitimatize one's identity as such. Interestingly, Zucker and Bay-Cheng (2010) found that men who self-identified as feminists were more likely to take public action in support of feminism than those who identified only as feminist allies. Despite this, comments from participants suggest that taking action is necessary to establish a feminist identity. This aligns with Tajfel and Turner's (1979) assertion that group membership requires both self-identification with a group as well as being an individual that is identifiable as part of that group. It should be noted that taking action is necessary in order to establish a feminist identity as perceived 
by participants and that the multitude of feminisms make it potentially difficult to establish a feminist self-identity for others. Also, the sentiment from participants does not necessarily acknowledge less overt feminist action or more introspective, individual action that might be far less observable to others.

A final major characteristic attributed to feminists focused on their behavior towards men. An attribute that merited a number of mentions by participants in the second and third focus groups, that was not raised in the first focus group, was the quality of aggression among feminists.

"I'm not an aggressive feminist, and I'm not someone who is against feminism" - Mark, Focus Group 1

A number of participants identified aggression as part of the negative stereotype of feminists, separating the stereotype from a more moderate and less confrontational conceptualization of a feminist. While other participants considered possible explanations for such an attribute noting that the feeling that no one is standing up for women or let alone their experience as women could be frustrating. While more gender-neutral language was used by participants discussing aggressive qualities of some feminists, references to why feminists might hold such a quality were however gendered female. Other references to aggression among feminists were more overtly gendered, as was seen in an exchange between participants in the second focus group.

Chris: "The feminazis?"

Aaron: "Yeah, where they hate men. They will discourage men from even being involved with them. But I think that that's kind of, like, such a small subset and really isn't all that big." 
While focus group participants primarily used gender-neutral language when referencing certain feminists who they perceived as aggressive, there were also instances where some participants referenced "aggressive" feminists as being against or attacking men. As the moderator for the focus groups, I understood these instances to be in reference to women identifying as feminists. It is unclear how my own identity as a woman potentially affected participants' use of gendered language.

\section{Men's Views on their Roles within Feminism}

The second research question sought to investigate what participants viewed as their roles within feminism. While many of the participants expressed uncertainty of how to participate in feminism, further discussion among each focus group saw some participants contribute their own perspectives which led to the generation of ideas by the group on how they could participate in feminism. Ways participants noted that they could contribute to feminism included calling out injustice when they encountered it, respecting women, recognizing issues of concern to feminism, and increasing one's own selfawareness. The examples participants used to illustrate how they could participate in feminism tended to emphasize reacting to situations as they presented themselves. This is potentially connected to the previously discussed importance of being action orientated as a feminist according to participants. Additionally, there was, albeit to a lesser extent, discussion of more self-reflective action that could be taken up by participants in order to take part in feminism. Examples of self-reflective action used by participants included furthering their own education on feminism, increasing their own self-awareness of feminist issues, and disrupting gender norms within one's own family. 
A theme that emerged from the larger discussion around the role of men in feminism was uncertainty around what men could do in order to participate. Four participants, three of whom were in the second focus group, expressed not knowing what action to take in order to support or participate in feminism.

“...I don’t know how I could help [feminism] as a guy.” - Rick, Focus Group 2

"It's almost like 'Hey, what can I do? I'm on the outside trying to help you." - Steven, Focus Group 3

Here participants directly indicated a sense of their male identity locating them outside of feminism. As previously discussed, some participants expressed their perception of feminism as not inclusive of men's issues as well as feeling excluded from feminism. Participants who expressed these sentiments were largely the same participants that expressed uncertainty of how to participate in feminism. This was especially relevant for participants who perceived their gender-identity to place them outside of the realm of feminism. The sense of exclusion from feminism seemed to lead participants to question what possible roles exist for them to take up within feminism. The relationship between non-identification with feminism and uncertainty around participatory action aligns with Zucker and Bay-Cheng's (2010) findings that not identifying with a group decreases the likelihood of an individual participating in a movement. Despite expressions of feeling excluded from feminism, there was also substantial discussion of identifying as either feminist or holding a pro-feminist identity.

While there was substantial discussion by participants around feelings of exclusion and uncertainty about how men could participate in feminism, there was also substantial dialogue among participants about how men could contribute to feminism. 
Each focus group addressed ways men could help feminism differently with each discussion leading to rich conversation involving the vast majority of participants. The first focus group centered their discussion on instituting small changes that would contribute to an eventual societal shift. This was discussed primarily through individual contributions that men could make by altering their own behavior and embodying the societal norms that feminism models:

"My girls are learning a different way than I grew up. My mom was a stay-athome mom until we were old enough to be on our own, then she went back to work. And I grew up in the 50's style, like I'd come home and she'd have the apron on and all that stuff. My girls don't see that, they see me making dinner and doing some of the "traditional" [participant used air quotes] housework that a woman would stay at home and do. And, so, part of this starts at home. We want to talk about all this change, but it's not going to happen if we're just talking about it and going 'Yeah, we should change things.'”-Grant, Focus Group 1

This quote, from the only participant who reported having children, was one of the few examples of specific proactive behavior that was mentioned by participants. Grant was very specific in articulating how he had adjusted his own behavior and works to share his personal experience, especially around his friends. Other participants made more generalized comments about not further contributing to issues:

"I would say that they way that I could help is A) not add to the problem and B) when I see issues try and call them out." - Aaron, Focus Group 2

During the second focus group, the discussion more pointedly addressed men's ability to take action in support of feminism through calling out instances of injustice and standing up for women. Participants also made note that this form of participation should include an effort to avoid personally contributing to those very issues, echoing the sentiment of including individual practice in one's daily actions which emerged during 
the first focus group. Overall, most participants in the study discussed ways to support women through their support of feminism and made no comments regarding how they could support men through supporting the movement.

Respecting women as a way for men to contribute to feminism was a prominent topic among focus groups. Conversations that formed around respecting women also emphasized the importance of supporting and defending women.

"As a guy, we can really just respect women for the most part. If there's an actual situation that comes up, then I guess we can help out. But everyday life just respect women is as far as we can go." - Warren, Focus Group 3

"I think respecting women in general is a good first step in showing you're supporting that cause [feminism]." - Dean, Focus Group 3

What was largely lacking in this conversation were specifics of what respecting women entails. Three participants in the first focus group echoed the sentiment that respecting women acts as contribution towards feminism, although these participants did not extrapolate on what constitutes such behavior. When I directly questioned participants about what respecting women entails, participants expressed the importance of treating women as equals while simultaneously remarking that their relationships with men were markedly different than those with women.

Overall, participants expressed primarily reactive behavior as a way to participate in feminism rather than positing behavior that could be considered more proactive. Participants who commented on reactive behavior were fairly vague about what actions they considered feminist. The lack of specificity could be explained by the myriad of different conceptualizations of feminism held by participants. An example of a possible avenue to take feminist action used by Chris in the second focus group was to bring 
attention to wage disparities within one's workplace. In response, Aaron voiced that he saw this as too much of a risk for himself and suggested an alternative that would pose less personal financial risk.

Aaron: "Hypothetical, if you have a co-manager, she's a woman and you find out you're getting paid more, maybe tell her so she can go to her boss and raise the issue. Just small things like that can, if everyone just kind of does small things, hopefully it can slowly build and get normalized. To where you can just help each other out in instances."

Chris: "I'd have to really hate my job to risk my job to...I don't know. I think a better road, if I was in a position of writing the paychecks, then I'd make sure that they were fair."

Overall, discussion around potential actions were focused in response to questions about how men could participate in feminism. As a result, the discussion concentrated around potential ways for men to participate.

Another area of emphasis among participants across focus groups was the importance of recognizing issues related to feminism as a way to contribute to the feminist movement. After likening men's privilege to the experience of being white and unaware of one's own white privilege because you do not face discrimination, Grant remarked that:

"It's tough, because I don't think most guys wake up in the morning and are, like, 'I have an advantage today."' - Grant, Focus Group 1

Similarly, another participant echoed the need to recognize an issue in order to address it.

"If you're not aware that's an issue, then it's hard to address it." - Chris, Focus Group 2

Participants also posited that increasing their own self-awareness as well as their awareness of culturally ingrained sexism as opportunities for men to contribute to 
feminism. A couple of participants noted that increasing their own awareness of feminism and feminist issues would be a way for men to contribute to feminism.

Participants likened a lack of awareness to white privilege, stating the difficulty in recognizing male privilege while in possession of it. Other participants went on to bring up the importance of taking responsibility for educating themselves on feminism and important feminist figures, but also noted that they were unlikely to follow through on such action. These suggestions could all be considered more proactive behavior, but the participants mostly simultaneously expressed the unlikelihood that such proactive measures would be taken. Instead, intervention on the behavior of other individuals was expressed as more feasible by a number of participants.

These areas of emphasis center around more individual level actions men could take regarding their own behavior, suggestive of a more proactive and self-directed approach to participation in either the support of feminism's goals or feminism itself. It is worth noting that the participants largely did not call their own behavior or actions into question, instead remarking more frequently on the presupposed perception of other men. Participants seemed to display an assumption that other men largely understand their behavior to be normative (Martin, 2001 as cited in Holmgren \& Hearn, 2009). The most distinctive self-examination came from Grant, from the first focus group, who spoke at length about his relationship with his daughters.

\section{Men Navigating Feminist Identity}

A number of emergent themes were revealed through the discussion among focus group participants. These themes coalesced around the navigation of a feminist identity 
as a man, either from participants' own experiences and identity as feminist or the participants' perception of how other men navigate a feminist identity. A significant aspect of the focus group conversations was centered around identifying as a feminist. This topic was discussed by participants with regard to both their personal perspective on adopting a feminist identity as well as their perception of other people's identities. Participants also discussed how they viewed people who proclaimed a feminist identity. While some participants expressed their perception that feminism has become more expansive and that a feminist identity is not dependent on gender identity, other participants in the focus groups specifically expressed not feeling able to relate to feminism because of their gender identity. What arose from the conversations among participants can be understood as utilizing different strategies to mitigate feeling excluded and/or out of place within a movement largely understood to be about women and for women and comprised of women.

Most prominently discussed by participants was their own navigation of whether or not they themselves adopted a feminist identity. While many participants readily identified as feminists, a number of participants expressed that they found the label of "equal-ist" to be a more accurate label. Perhaps due to understanding a male identity as locating themselves outside the boundaries of feminism, participants expressed that “equal-ism" was, essentially, an expanded, more inclusive feminism. The use of the "equal-ist" label allowed participants ensure their own inclusion despite feeling like outsiders to a movement that they viewed themselves as supporting, but were either unwilling or, perhaps, felt unable to identify with directly. This is supported by the 
participants statements as well as the pre-survey which showed that participants who expressed an "equal-ist" identity did not identify as feminists but did indicate strong support for feminism.

Taking action was also established as a prototypical feature of feminists by focus group participants. This perception was further discussed with particular concern when it came to men who identified as feminists. For example, participants established taking action as necessary for men who claimed a feminist identity in order to prove that they were enacting a feminist practice. In other words, a feminist practice had to be made visible to others to verify oneself as a feminist, especially as a man. This supports that being a woman is a prototypical feature of feminist. Thus, participants saw men, as a nonprototypical feminists, as having to legitimize their claimed feminist identity through the performance of taking feminist action.

A man's connection to women was another avenue noted by participants that could be utilized to establish a feminist identity as a man. Close family or romantic ties to women were noted by some participants as their own route to learning about feminist and adopting a feminist identity or perceived by other participants as the reason held by feminist men for adopting that identity.

Perhaps related to participants' feelings of existing outside of feminism, there were a number of participants who felt their support of equality was a better description of their views. Despite the number of participants who specifically expressed their feelings that feminism was not bounded by gender, there was more frequent discussion 
around the desire for an option centering around equality for everyone. These participants expressed a desire for a more inclusive term to capture equality among all people.

"I would just say that I'm for equality for everyone. Not just feminist. So, I mean, if I was self-describing myself, I wouldn't say I'm a feminist, but I would say I am for equality for everyone, not just women, necessarily, but for everyone."

- Warren, Focus Group 3

Warren expressed a sentiment shared by a number of participants, a reluctance to identify as feminist but still wanting to voice support of equality. This sentiment was shared by a number of participants who noted that an "equal-ist" identity was a better descriptor of their stance. Potentially to mitigate the feeling that a male identity places themselves outside of the boundaries of feminism, a proclaimed "equal-ist" stance was a way for participants to expand the perceived boundaries of feminism to include their own male identity. In other words, participants who purported an "equal-ist" stance saw themselves as feminists, but understood themselves to not be seen as feminists by others. Thus, participants combatted the perceived boundaries of feminism by extending the boundary outward to include themselves through a stance that they termed "equal-ist." To participants an "equal-ist" was not un- or anti-feminist, but an expanded feminism that would include their own identities, thus allowing them to participate in feminism.

Additionally, support of equality may be connected to feminism's current popularity, which could contribute to participants' identification with feminism either as feminist or, more broadly, as an "equal-ist." The social prominence of feminism was repeatedly remarked on by participants as an important aspect of the movement.

"The hip thing is to champion social justice right now." - Chris, Focus Group 2 
"It [feminism] seems like, it's more like, the most popular side right now."

- Kevin, Focus Group 2

This perhaps suggests that there is a social judgement against individuals who do not express either a pro-feminist ideology or feminist identity. Possibly in conjunction with feminism's current prominence, a number of participants stressed that adopting a feminist identity was not as important to them so much as working to support feminism as a movement. Participants expressed support for feminism while remaining reluctant to identify as feminist. The following excerpt from the third focus group illustrates this reluctance among participants.

Dean: "It's not a label I would use for myself, but it's just not the way I use that, that terminology. I agree it's not a gender specific thing, it's just, I don't feel like..."

Rob: "It's just not how you [Dean] self-identify."

Dean: 'Because I wouldn't go out and say around 'I'm a feminist' but, I support the [feminist] group or movement. I'm not in every group I believe you know?"

Dean expresses feeling able to support feminism without necessarily being part of feminism as a group. The identity of feminist is not important to him and he does not feel it describes him, but still views himself as supporting feminism. This is in line with Breen and Karpinski's (2008) study which found that men held liberal feminist attitudes but did not identify as feminists. A number of participants that expressed a reluctance to selfidentify as feminists felt that the supporter of equality sentiment previously discussed was a more appropriate identity for themselves than feminist. One such participant, Rick from the second focus group, stated that one's belief in equal rights is what makes someone a feminist and that "Whether you voice it [being a feminist] or not is a different concern." 
Supporting equality was perceived by these participants as working in support of feminism, thus removing the need to self-identify as feminist. A reluctance to adopt a feminist label by participants may also be a result of feeling excluded from feminism as men.

Another aspect of negotiating feminist identity as a man discussed by participants was the importance of taking action in establishing a feminist identity. As described above, the first and third focus groups emphasized taking action as a feminist trait. While gender neutral language was generally used to talk about the importance of taking action, particular emphasis was made regarding men's actions being perceived as aligning with a participant's understanding of feminism. The following exchange took place in the first focus group and illustrates the perceived necessity of action in establishing oneself as a feminist:

Dan: "I support it. I mean, if they [men who identify as feminists] have that mind set. And they [feminists] believe in certain principles, and they act on that when they have the opportunity to, kind of like what was explained a little bit. I think that that's just fine."

Russel: "I think it's one thing to say it, but it's another thing to actual do it." In response to a direct question on what participants thought of men who refer to themselves as feminists, these participants emphasized the need for men's actions to reflect their claimed feminist ideals. This suggests that some participants saw a greater need for men to prove their feminist identity, an identity that must be earned instead of merely claimed. Russel went on to emphasis his sentiment, stating that "If a man is going to call himself a feminist, please show it with your actions, not just with your words." 
Participants also expressed that failing to take action undermines claims to feminist identity. Participants in the third focus group further expressed that action, specifically standing up for women's rights, was necessary in order to be considered a feminist:

Ben: “...but I don't see how you can be a feminist if you wouldn't stand up for their rights, you know what I mean?"

Rob: "Yeah. Totally, completely agree."

This suggests that participants potentially perceive failing to take action as negating a claimed feminist identity. As previously discussed, participants articulated that feminist action as necessary to legitimize a claimed feminist identity, especially as a man.

Another method for legitimizing a feminist identity as a man that was discussed among participants was the use of personal connections to women. During the focus groups, a number of participants stated their personal connections to women as their primary reason for identifying as feminists, while other participants posited these connections as what other men use to justify their feminist identities. Given the previous discussion of some participants feeling that they felt outside of feminism's realm as men, it is possible that participants view men's relationships with women as inroads to establishing a connection to feminism.

Members of the first focus group centered their discussion of identifying as a feminist on their relationships to daughters and sisters. Conversely, participants in the third focus group focused on family and friends with less denotation of gender but without any distinct mention of men. Finally, the second focus group's conversation primarily centered on why other men identify as feminists, citing family ties and female 
significant others. During conversation among participants about whether feminism was social evolution or just a current trend, a participant put forth his reason for not connecting with feminism and his experience with men who do connect to feminism:

"It's hard for me to get behind a certain group's agenda that doesn't directly apply to me. Then again, I'm a selfish human being, I'm not that altruistic. And when I hear other men that are passionate about feminist causes, it's, in the same sentence, 'because I have a daughter' or 'because I have a mother.' So, it's in direct relation to their family." - Chris, Focus Group 2

Chris saw feminism as not applying to him directly due to his gender identity.

Interestingly, Aaron, a fellow participant who spoke positively about feminism and identified as a feminist, defended Chris as merely "not a feminist" rather than "antifeminist." Chris voiced his perspective that men who participate in feminism do so because of familiar relationships with women. Aaron went on to comment that he perceived having familiar relationships with women as motivation in response to the prompt of what reasons a man would have for being a feminist. He also suggested a man's own personal experience might be a contributing factor but could speak for that because he saw his own connection to feminism established through his romantic relationship with a woman:

"Like you [Rick], having, sisters, daughters, girlfriends, wives, whatever, mom, that you want that for them. Having just that personal experience, maybe. Where it's just I want this for them too. I can't really speak for myself, because for me it was a girlfriend who got me into it." - Aaron, Focus Group 2

As the female moderator, I did not push on whether participants felt the only way men could identify with feminism was through their personal connection to women. Rather, participants expressed this sentiment both in response to the question of what reasons a man might have for being a feminist and more emergently while conversing with other 
participants in response to preceding moderator questions. Aside from ungendered mentions of friends and family, there were no comments that indicated that a man might identify as a feminist out of his own self-interest or that such an identity would be motivated by his personal connection to another man. It should be noted that participants only credited family and female significant others as influencing their knowledge of and relationship to feminism. No mention was made of feminism being related to through female friends, suggesting that either a familial or romantic interest was necessary to motivate involvement with feminism. Additionally, interaction with feminism was never attributed to any type of connection with a male figure. 


\section{Chapter 5: Discussion}

\section{Summary of Research Questions}

The first research question sought to explore the definitions of feminism expressed by focus group participants. Given the plentitude of feminisms, both academic and popular, it is informative to gain some insight into which feminism are understood and articulated by men. Participants discussed how feminism has grown to encompass a broader range of identities and issues than just those related to women. While many participants expressed that they understood feminism to be ungendered, other participants pushed back against this. Both feelings of exclusion from and inability to relate to feminism by other participants stand counter to other participants' perception of more expansive feminisms. Participants also voiced the opinion that feminism primarily stands to benefit women. While some participants saw feminism as benefiting men through the dissolution of gender norms, most articulations of benefits to men by participants were seen as a side benefit of feminism's positive effect on women.

Definitions of feminism expressed by participants were connected to describing characteristics of prototypical feminists. Two feminist prototypes emerged from the first research question, taking action and aggression. Feminist prototypes proved more difficult to ascertain from participants' responses to questions about what qualities participants associated with feminists. One prototype that did emerge from more direct questioning was aggression. While the aggressive quality of feminists was primarily mentioned using gender-neutral language, specific statements as well as further elaboration by participants established this quality as primarily associated with women. A 
second prototype that emerged from the focus groups was taking action. Participants repeatedly stated that taking action through standing up for women and taking advantage of opportunities as a requirement for feminists. Moreover, a number of participants expressed that a stated feminist identity could be negated without the accompanying, as perceived by participants, feminist action.

In order to explore how men might perceive feminism, the second research question sought to explore what participants felt their roles are in feminism. While there was a substantial expression of uncertainty of how to participate in feminism as men, further discussion revealed various opportunities for men to engage with feminism. Perhaps contributing to this uncertainty for participants was the feeling of being outside the realm of feminism as men. Participants often noted that they felt that their support of equality as well as respecting women as contributing towards feminism. While conversations among participants primarily focused on more reactive behaviors as their potential role in feminism, there were some participants that expressed more proactive actions. Increasing one's awareness of issues faced by women, further educating oneself on feminism, acknowledging one's own privilege, and disrupting gender norms were all either posited or put into practice by a number of participants in the focus groups.

\section{Men's Relationship to Feminism}

Focus group participants identified feminism as inclusive, noting that feminism encompasses issues regarding race, immigration, and LGBTQ rights. Interestingly, despite over half of the participants identifying as feminist in pre-screening survey, a number of participants directly stated that they felt excluded from feminism due to their 
gender. Additionally, participants who expressed that feminism was inclusive of men noted elsewhere in the focus group discussions that they felt like outsiders to feminism. Participants who expressed feeling like outsiders later went on to identify their gender as largely responsible for their perceived disconnection to feminism. These participants failed to address the dissonance between their statements, feeling both excluded from participating in feminism due to their gender and that feminism is inclusive to men.

When asked, focus group participants largely articulated expansive views of feminism, noting that feminism goes beyond women to encompass marginalized identities. Some participants went on to further expand feminism as inclusive of men. Despite some participants articulating feminism was inclusive and over half of the participants identifying as feminist in the pre-screening survey and focus groups, there was substantial discussion of feminism not including men. Both participants that identified as feminists and those who did not expressed an uncertainty of what to do in order to participate in feminism and the extent to which men are included within it. While feelings of exclusion were frequently expressed, participants did not fully elaborate on why they felt alienated and excluded from feminism. Many expressed, however, that their male gender positioned them outside the feminist movement.

The dissonance among participants perhaps corresponds to the conceptualization of feminism as a female only sphere (Anderson, 2009; Breen \& Karpinski, 2008; Toller et al., 2004; Sutter \& Toller, 2006; Williams \& Wittig, 1997). Other participants argued that "white men" were less included than men of other ethnic and racial groups. This possibly suggests that there is a perception that marginalized groups are encompassed 
within feminism and that men's inclusion necessitates intersection with a marginalized identity. In other words, feminism is perceived as more inclusive of men who are marginalized by their race, ethnicity, or other form of social stratification. Unlike previous studies, focus group participants did not establish a feminist identity as challenging their masculine identity (Wiley et al., 2012; Toller, Suter, \& Traitman, 2004). Rather, not being a woman omitted men from participation in feminism and, according to some participants, identification as a feminist. This aligns with Breen and Karpinski's (2008) findings that perception of feminism as limited to women challenges men's inclination to identify with the movement.

Even though participants expressed having a difficult time identifying as a feminist, they did feel they could enact a feminist practice, specifically through standing up for women's rights, respecting women, and educating themselves about "feminist" issues. Participants noted that an individual's actions were essential in establishing a feminist identity. One could not simply say he was a feminist without simultaneously displaying a feminist practice. Participants may feel, due to their gender, that a feminist practice must be displayed through action because merely identifying as a feminist will not be trusted by prototypical feminists or other men. However, it is unclear whether participants understood their actions would be understood as feminist by prototypical feminists and outside observers. Future research could both investigate what is understood as a feminist practice and if men enacting that practice would be identified as feminist. 
Connected to participants' expressions of uncertainty around their inclusion in feminism was a similar uncertainty around how to participate in feminism. As Zucker and Bay-Chen (2010) asserted, the lack of ability to identify with a group or movement would have a negative impact on the likelihood of participation in social action connected to that movement. In other words, the inability to self-identify as a feminist causes hesitation in how to participate in the feminist movement. This could speak to participants having uncertainty about when their participation is presumable and identified as enacting a feminist practice.

Although some participants felt that feminism accurately encompassed their political beliefs, there were a number of participants identified an "equality for everyone" stance as more descriptive of their position. Many of these participants were reluctant to identify as feminists, but asserted that the stance of "equality for everyone" included women as well as other identities. This suggests that these participants perceive that “equality for everyone" or being an "equal-ist" as encompassing a greater range of identities, thus making it a more inclusive stance than feminism or being a feminist. The view of there being a more inclusive label than feminism/feminist insinuates that these terms still carry the presupposition that they are restrictive to women's concerns of equality. My impression from the focus groups was that an equality-for-everyone stance was considered more inclusive and more progressive than a purely feminist stance. Equality of everyone seemed to imply a broader consideration and incorporation of various identities and thus less restrictive then feminism. 


\section{Social Identity Theory and Feminism}

Some of the participants expressed that they did not identify as feminist, but did perceive themselves as being in support of feminism. According to Tajfel and Turner (1979), essential to group membership is that an individual is both identifiable with the group identity and perceives themselves as part of the group. The perception among some of the participants was that they were not feminists, not part of the group, but that their support of the group and/or belief in equality aligns them with feminism. Given these participants support for feminism and/or equality for all, an outside observer might categorize them as feminists. However, according to Tajfel and Turner (1979), being defined by others as part of a group alone is not enough to dictate group membership. Internalization of group membership as part of an individual's self-concept must occur in addition to identification by others as part of the group (Tajfel \& Turner, 1979). In other words, using Tajfel and Turner's (1979) definition of group membership, an outside person might categorize these participants as feminists based on their support and/or beliefs, but the individuals themselves do not understand themselves to be part of that group. Thus, these participants are not feminists since they do not understand themselves as such. However, participants do seem able to label their actions as feminist. This contradicts Hogg's (2006) assertion that individuals will not behave as group members without first identifying with that group. In other words, men who do not self-identify as feminists would not be expected to participate in feminist practice.

Despite expressed uncertainty around participation, there was still ample discussion of ways participants saw themselves as able to enact feminism. Participants 
primarily discussed their ability to participate in feminism through individual efforts to alter their own behavior to better conform to feminist ideals. Next, they also expressed the importance for men to develop and acknowledge the societal effects of gender, specifically their own male privilege. While participants largely focused on the ignorance of other men, there were instances where participants noted the importance of increasing their own self-awareness. For participants, taking action seemed to be primarily connected to outward signs of supporting women despite more extensive discussion of introspective self-work. Participants who mentioned individual self-work noted that alteration of their own behavior was a means to avoid further exacerbating, rather than actively combating, social inequality between genders. It is possible that men see their ability to contribute to feminism as action-oriented, but do not perceive more individuallevel self-reflection and alteration of their own behavior as equivalent to feminist action.

Participants seemed to indicate that they needed two things simultaneously to identify as a feminist. First, participants held a need for their identity to be viewed as included within the societal and group understanding of who could be a feminist. Second, participants expressed a need to feel that their self-identification as feminist would be accepted by prototypical feminists. In other words, some male participants did not feel they can take up the label of feminist because they would not be accepted as such by prototypical feminists. Thus, the perception of how much group members are willing to accept an individual's adoption of a group label is equally important to how willing an individual is to adopt a group label. This relates to Tajfel and Turner's (1979) assertion that individuals strive to maintain a positive self-concept, where perceived group 
rejection negatively impacts their conception of self. Largely the men participating in this study felt that they can do a feminist performance, but are not sure that their performance will be understood as such by the prototypical feminist.

As previously discussed, Tajfel and Turner (1979) stated that group membership requires that both individuals themselves and group members to recognize an individual as part of the group. Participants saw themselves as able to an enact feminism, but have varying degrees of uncertainty of whether their actions will result in their identification as feminists by prototypical feminists. This is an interesting point of uncertainty among participants given that there are prominent feminist thinkers who state that not only can men be feminists, but that men should be feminists. Additionally, these same prominent feminists see men's issues as incorporated into feminist political ends. These assertions by prominent feminist thinkers would suggest that there is the potential for men to be viewed as feminists by existing feminists. This establishes one half of what necessitates group membership according to SIT.

Furthermore, participants were more willing to adopt what they perceived as feminist action rather than necessarily take on a feminist label. This contrasts previous findings that connect self-identification as feminist with an increased likelihood of participation in feminism (Williams \& Wittig, 1997; Zucker \& Bay-Cheng, 2010). This suggests that what participants' perceived as feminist action was more accessible for them to adopt than a feminist identity. That participants would behave as feminists without necessarily identifying as feminist contradicts Hogg (2006) assertion that people will not behave as part of a group without first identifying themselves as part of that 
group. It is also interesting to note that participants did not view claiming a feminist identity as enough to be considered a feminist, to be a feminist, according to participants, required action to authenticate a feminist identity.

Perhaps a component of group membership not fully captured by SIT is that in addition to recognition of oneself and by others as part of the group, the individual also must perceive that others will identify them as part of the group and not reject them. One way participants authenticate their identity as feminist is through their personal relationships with women. Discussion among the focus group participants regarding adoption of either a feminist or pro-feminist identity by men was attributed to direct personal relationships with women. Participants in all three focus groups noted personal relationships with women as the motivational force for men to adopt a feminist identity or stance. Throughout these conversations, while more gender-neutral influences were mentioned a handful of times, no mention of any personal relationships with other men as motivating or influencing a pro-feminist or feminist identity was made. Furthermore, none of the participants posited themselves and their own social position as motivational in the adoption of a (pro-) feminist identity. The lack of participants' attribution of connections to feminism through personal relationships with other men, whether that it through fathers, sons, or their peers, is noteworthy. This omission perhaps speaks to men being largely perceived as problematic to feminism rather than standing to contribute and benefit from it alongside women (Herbert, 2007). Further research could explore perceptions of men who attribute their own (pro-)feminist stance as a result of their male identity or as motivated through the influence of other men. 


\section{Feminist Prototypes}

Two feminist prototypes were established from the focus groups, aggression and action orientation. Aggression as a feminist prototype is unsurprising given pre-existing negative stereotypes of feminists as angry and combative (Buschman \& Lenart, 1996; Toller, Suter, \& Trutman, 2004; Zucker, 2004). The primary prototype established by the focus group participants was that feminists are action oriented. According to participants, to be feminist is to exhibit feminist principles through lived actions, rather than through verbalizing a feminist stance alone. Thus, one is able to establish a feminist identity through taking action, especially when instances of inequality are encountered.

Participants deemed expressing a feminist identity without either taking feminist action or acting in a manner counter to feminism as undermining a self-attributed feminist identity. This perhaps shows the potential awareness among men of the seemingly low standards for men to gain access to feminist spaces through the expression of a feminist ideology without exhibiting corresponding behavior (Holmgreen \& Hearn, 2009).

Given the focus group dialogues, it was unclear whether or not participants understood the feminist prototype of taking action as attainable for men. However, participants expressed that they did not consider a feminist stance to be gendered. Despite this, participants from all three focus groups identified feeling like outsiders to feminism largely due to their gender. This suggests that men recognize feminism as gender inclusive, but experience dissonance around their actual involvement. There was substantial discussion by participants about the importance of taking action over 
identification as a feminist, as well as the identification of "hypocritical feminists," suggesting that participants in this study define a feminist identity through action.

Men participating in the study saw themselves as able to participate in feminism without adopting a feminist identity and provided ways in which they conceived of themselves as contributing to feminism as a movement. This potentially contests the idea that identifying with the movement is a stronger indication of likelihood of participation in feminist social action (Zucker \& Bay-Cheng, 2010). Despite identifying that feminism includes men there was no discussion by participants of how feminism might address issues faced by men and only limited dialogue on how gender stereotypes negatively impact men. The discussion surrounding the impacts of feminism focused on improving the lived experience of women and failed to acknowledge how this could simultaneously benefit men (Herbert, 2007). There were two mentions by participants that acknowledged the restrictive qualities of gender expectations on men, but these comments were brief and not taken up by the larger group in either instance. Overall, participants did not acknowledge how notions of and pressure to perform masculinity might be challenged through feminism, perhaps giving rise to alternative masculinities (hooks, 2001a).

A third possible feminist prototype was female. Discussion of who feminists are were gendered female by participants. This was achieved in three ways. First, participants expressed feeling excluded from feminism due to their gender. Second, participants noted the potential inability to have their feminist practice recognized as feminist. Third, feminism is perceived as more inclusive of men who are marginalized by their race, ethnicity, or other form of social stratification. Although not indicated through explicitly 
noting that feminists are women exclusively, participants did not gender feminists as men but did gender feminazis as women. Previous research (Anderson, 2009; Breen \& Karpinski, 2008) has found that feminist and feminism is gendered female and other research (Toller, Suter, \& Trautman, 2004; Suter \& Toller, 2006) has found that men that do identify as feminist are seen as highly feminine. Given the previous research and my understanding of feminism, I am inclined to believe that participants indirectly indicated that an established feminist prototype they hold is that feminist are women.

\section{Reflexivity}

A reflexivity section is meant to outline the researchers relationship to and impact on the knowledge production process. This section aims to highlight some of the ways my positionality, understanding of feminism, and changing relationship to the definition of feminism impacted the data gathering process and my analysis and interpretation of the data.

One of my motivating factors for this study was to understand how men understood their relationship to feminism. I wondered if they understood feminism through current popular conceptualizations of feminism or more academically inclined ones and how that impacted their ability to self-identify as feminist. Coming into this study, I operated with a definition of feminism that fully incorporated men. I believed that men can and should have a role in the feminist movement and should feel able to identify as a feminist. I carried this definition throughout the construction of my moderators guide and analysis of the data. My stance did not change throughout the course of the study; however, my conceptualization of feminism(s) did expand. 
Throughout the course of this study, I became more cognizant of the varying definitions of feminism(s). The definitions are ethereal, shifting, and changing, without a set form. As I conducted the literature review and the research for this study, I felt my own relationship to and understanding of feminism shift. The ambiguity of the definition and the set of actions and politics connected to being a feminist set in, leading me to interrogate what it means to be a feminist. The shifting and ambiguous grounds of feminism, identifying as a feminist, and enacting a feminist practice were also explicated and felt by the participants in the study.

This study was not about my definition of feminism or placing that definition onto the participants. I do not believe that much is gained from stating where I draw the boundaries of feminism for myself. This study is about establishing where others define the boundaries of feminism and their own relationship to feminism. Throughout the course of constructing the moderators guide, conducting the focus groups, analyzing the data, and writing of this document, I tried to honor the participants' voices. I do, however, recognize that my familiarity with academic definitions of feminism and personal support of men being able to identify as feminist impacted the themes I saw emerge from the data.

Within the focus group setting, my positionality and the possible perception that I myself am a feminist, could have impacted how participants discussed their relationship to feminism amongst one another. I made conscious efforts to minimize my impact on the discussion among participants by making every effort to minimize being seen as an authority on the subject. Some could conjecture that having a woman present in the room 
would always already impact how men discuss the topic of feminism. The female gaze in this instance would be felt by male participants, making them hyperaware of themselves because of my presence in the room.

The role of the female gaze in shaping how the participants discussed feminism and their ability to identify as feminist amongst one another may not have had a large impact on the data collection process. First, when asked how they identified (in regards to feminism) in the focus group, none of the participants changed how they responded from the pre-screening survey. This seems to speak to the comfort of the participants being able to openly discuss the myriad of ways they identified with and practiced feminism. Next, the dynamics of the focus group may be mediated by other existing social structures. Patriarchy permeates all spaces. This especially is illustrated through the perception of my authority on feminism, assumed feminist identity, and the potential impact on men's discussion of feminism and feminist identity. The structure of society places me in a position to claim expertise in feminism due to my gender. However, I am not willing to make such a claim myself even if others might assume as much. This project has been an exercise in exposing myself to the variety of feminism rather than asserting any one understanding of feminism.

\section{Limitations and Future Research}

A variety of challenges presented themselves to this study. Primarily, there was a difficulty in recruiting Millennial male participants. The study drew participants from the same geographical, urban region of the Pacific Northwest. Such a sample fails to capture or attend to the diversity of opinions and perspectives held by men from different regions 
and urban centers throughout the United States. This study does not address the effect of place on the perspectives and identities expressed by the study's participants. This study drew a small sample from a relatively homogenous population, one that did not allow for or pursue an interrogation of race and its intersection with gender, especially with regard to feminism.

Concepts of masculinity may impact the way men identify with feminism. This study did not fully address the participants' conceptualizations of masculinities or how they perceived their own masculinity. If conceptions of masculinity are tied to the possibility for men to identify as feminist, individually and/or collectively, then further understanding the relationship between masculinities and political practice warrants further study. Further research could also explore the masculine identities held by men and their impact on men's enactment of feminist practice.

This study primarily focused on men's individual relationships with feminism and their participation in the feminist movement. Although important, this overlooked ways in which men can collectively engage with feminism. The patriarchy is often perceived as a collective of men. Men collectively acting together is often viewed as an embodiment of patriarchy. Perhaps the mass organization of men is perceived as the mass organization of patriarchy, even if they intend to collectively act to support the feminist movement. Men possibly feel a reticence about collectively engaging in feminism, in a way that they may not feel as an individual because collective action as men is problematized by feminism as patriarchal. This suggests a felt inability by men to work collectively to engage in feminist social action and forge a feminist identity through their collective 
action. This potentially truncates men's ability to achieve Hogg's (2006) fourth type of social identity, where collective identities are forged through engaging in social action. This points to two possible lines of research to further understand how men perceive they can or cannot work together to enact a feminist practice. First, research on how men collectively enact a feminist practice could address some of the potential qualms men have about being perceived as enacting patriarchy by feminist. Second, further research could explore perceptions of men who attribute their own (pro-)feminist stance as a result of their male identity or as motivated through the influence of other men.

Regardless of how men collectively identify with feminism, more research is needed to see if changing perceptions of who feminism stands to benefit could decrease the feelings of alienation and exclusion from feminism expressed by men. A major question that remains unanswered is whether showing of how feminism can benefit men increase men's participation in the feminist movement. Further exploration of this is necessary to establish whether efforts to promote the understanding of feminism's potential to benefit men through addressing issues surrounding gender. Regardless, more research is needed to see if changing perceptions of who feminism stands to benefit could decreased the feelings of alienation and exclusion from feminism expressed for men. Furthermore, absent in the discussion was any acknowledgement that taking action around men's issues could be considered a feminist act.

The willingness of participants to identify as feminists despite feelings of alienation from feminism is interesting given previous studies that found a reluctance to self-identify as feminists among participants. While this is still exploratory, further 
research is warranted to explore a potential shift in perception of feminist identity from previous studies. While this study sought to explore whether men think they can be feminist, future study should investigate whether men think that prototypical feminist think that men can be feminist. This ties to a broader question of whether or not outside group members feel like they will be understood by current group members as part of the group and capable of enacting authentic social action. It is not necessarily whether or not group members do or do not identify an outsider as part of the group, but whether potential outsiders to the group feel as if they will be understood as part of the group. SIT perhaps does not fully address the importance of an individual feeling that they will be identified by the prototypical group member as part of the group.

\section{Conclusions}

According to van Stekelenberg and Klandermans (2013), identification with social movements is a stronger indicator of participation in social action than identification with social categories. Since participants saw themselves as able to participate through feminist practice without necessarily identifying as feminist themselves, this study problematizes the use of identification with a movement alone as a predictor for participation in an identity-based movement. If identification with a movement is not necessarily a predictor of participation in some social movements, what other factors can be identified as motivating participation?

This study found that the participants' relationship to feminism was influenced by their gender and, despite this, participants felt that they could enact a feminist practice. Additionally, using SIT as a framework to understand the varied ways in which 
participants either identified with or in relation to feminism, I found that it was important for participants that they felt that they would be seen as feminists by prototypical feminists. This is evidenced also in the interview with Rhys Atkinson, one of the individuals pictured in the viral image of six male Centennial High School student athletes standing in the boys' locker room wearing "WILD FEMINIST" tee-shirts (Acker, 2016; Vagianos, 2016). Atkinson states that “...it has to be known that there are men out there that support women and women's rights" (Vagianos, 2016). This statement speaks to the perceived need that men be understood and seen by feminists as group members. And, perhaps, implies the fact that there are such men is not known or in doubt.

By actively identifying as feminist, Atkinson, who "believe[s] in the equality of everyone," and his fellow athletes are making a powerful statement not only the about treatment of women, but about who gets to be a feminist (Vagianos, 2016). Given that some participants in this expressed uncertainty about being identified as feminists by others, this perhaps is part of the increased popularity of "WILD FEMINIST" $t$-shirts and other material goods that aid in the identification of individuals as, potential, feminists. The "equality of everyone" sentiment expressed by Atkinson was echoed within the focus groups of this perhaps speaks to the current prominence of feminism in American culture. Feminism is currently a prominent topic in the news, social media, and, increasingly, clothing and other material goods. Participants themselves identified feminism as being "the popular side" currently in addition to asserting that "the hip thing is to champion social justice." 
As this study and example illustrate men's relationship to feminism is mediated not only their own identities, but the perception of others. Those whose identities do not match the prototypical member of an identity-based movement are left to question not only whether they can participate, but whether that participation will be seen as in-line with that movement's practice. This question also speaks to the potential for non-identity aligned individuals to fear rejection for attempting to participate with that identity-based movement, undermining their self-efficacy. The feeling that their participation will be accepted thus determines their perceived ability to participate in an identity-based movement. 


\section{References}

Acker, L. (2016, October 20). Oregon high school athletes rep feminism in the locker room. The Oregonian/OregonLive. Retrieved from http://www.oregonlive.com/trending/2016/10/oregon_high_school_athletes_re.ht $\mathrm{ml}$

Alfonso, R., \& Trigilio, J. (1997). Surfing the third wave: A dialogue between two third wave feminists. Hypatia, 12(3), 7-16. Retrieved from http://www.jstor.org/stable/3810219

Anderson, V. N. (2009). What's in a label?: Judgments of feminist men and feminist women. Psychology of Women Quarterly, 33(2), 206-215. doi: 10.1111/j.14716402.2009.01490.x

Bennett, J. (2016). Feminist fight club. New York: Harper Collins.

Brah, A., \& Phoenix, A. (2004). Ain't I a woman? Revisiting intersectionality. Journal of International Women's Studies, 5(3), 75-86. Retrieved from http://vc.bridgew.edu/jiws/vol5/iss3/8

Braun, V., \& Clarke, V. (2006). Using thematic analysis in psychology. Qualitative Research in Psychology, 3(2), 77-101. doi: 10.1191/1478088706qp063oa

Breen, A. B., \& Karpinski, A. (2008). What's in a name? Two approaches to evaluating the label feminist. Sex Roles, 58(5), 299-310. doi: 10.1007/s11199-007-9317-y

Brown, R. (2000). Social identity theory: Past achievements, current problems and future challenges. European Journal of Social Psychology, 30(6), 745-778. doi: 10.1002/1099-0992(200011/12)30:6<745::AID-EJSP24>3.0.CO;2-O 
Burns, S. M., Aboud, R., \& Moyles, C. (2000). The relationship between gender social identity and support for feminism. Sex Roles, 42(11-12), 1081-1089. doi: 10.1023/A:1007044802798.

Buschman, J. K., \& Lenart, S. (1996). "I am not a feminist, but...”: College women, feminism, and negative experiences. Political Psychology, 17(1), 59-75. doi: $10.2307 / 3791943$

Butler, J. (1988). Performative acts and gender constitution: An essay in phenomenology and feminist theory. Theatre Journal, 40(4), 519-531. Retrieved from http://www.jstor.org.proxy.lib.pdx.edu/stable/3207893

Butler, J. (1990). Gender trouble: Feminism and the subversion of identity. London: Routledge.

Cameron, J. E., \& Lalonde, R. N. (2001). Social identification and gender-related ideology in women and men. British Journal of Social Psychology, 40(1), 59-77. doi: $10.1348 / 014466601164696$

Cohn, A. M., Jakupcak, M., Seibert, L. A., Hildebrandt, T. B., \& Zeichner, A. (2010). The role of emotion dysregulation in the association between men's restrictive emotionality and use of physical aggression. Psychology of Men \& Masculinity, 11(1), 53. doi: 10.1037/a0018090

Courtenay, W. H. (2000). Constructions of masculinity and their influence on men's well being: A theory of gender and health. Social Science \& Medicine, 50(10), 13851401. doi: 10.1016/S0277-9536(99)00390-1 
Cowan, G., Mestlin, M., \& Mesak, J. (1992). Predictors of feminist self-labeling. Sex Roles, 27(7-8), 321-330. doi: 10.1007/BF00289942

Crawford, M. (2002). Gender and humor in social context. Journal of Pragmatics, 35, 1413-1430. doi: 10.1016/S0378-2166(02)00183-2

DeFrancisco, V., \& Palczewski, C., (2014). Developing a critical gender/sex lens. In V. DeFrancisco, et al., (Eds.), Gender in communication: A critical introduction (pp. 3-26). Thousand Oaks, CA: Sage.

Dill, B. T., McLaughlin, A. E., \& Nieves, A. D. (2007). Future directions of feminist research: Intersectionality. In S. N. Hesse-Biber (Ed.), Handbook of feminist research, theory and praxis (pp. 629-638). Thousand Oaks, CA: Sage.

Edley, N., \& Wetherell, M. (2001). Jekyll and Hyde: Men's constructions of feminism and feminists. Feminism \& Psychology, 11(4), 439-457. doi:

$10.1177 / 0959353501011004002$

Eisele, H. \& Stake, J. (2008). The differential relationship of feminist attitudes and feminist identity to self-efficacy. Psychology of Women Quarterly, 32(3), 233244. doi:10.1111/j.1471-6402.2008.00432.x

Ellemers, N., \& Haslam, S. A. (2012). Social identity theory. P. A. M. van Lange, A. W. Kruglanski, \& E. T. Higgins (Eds.), Handbook of theories of social psychology (v. 2, pp. 379-398).

Fernandes L. (2010). Unsettling "third wave feminism": Feminist waves, intersectionality, and identity politics in retrospect. In N. A. Hewitt (Ed.), No 
WHAT'S NEW PUSSYHAT?

permanent waves: Recasting histories of U.S. feminism, (pp. 98-118). London: Rutgers University Press.

Fitz, C. C., Zucker, A. N., \& Bay-Cheng, L. Y. (2012). Not all nonlabelers are created equal: Distinguishing between quasi-feminists and neoliberals. Psychology of Women Quarterly, 36(3), 274-285. doi: 10.1177/0361684312451098

Freedman, E. B. (2002). No turning back: The history of feminism and the future of women. New York: Ballantine Books.

Hancock, A.M. (2013). Empirical intersectionality: A tale of two approaches. UC Irvine Law Review, 3(2), 259-296. Retrieved from: http://scholarship.law.uci.edu/ucilr/vol3/iss2/6

Hancock, A. M. (2015). Intersectionality: An intellectual history. New York: Oxford University Press.

Hannah, D. R., \& Lautsch, B. A. (2011). Counting in qualitative research: Why to conduct it, when to avoid it, and when to closet it. Journal of Management Inquiry, 20(1), 14-22. doi: 10.1177/1056492610375988

Herbert, L. A. (2007). Taking 'difference' seriously: Feminisms and the 'man question'. Journal of Gender Studies, 16(1), 31-45. doi: 10.1080/0958923060116141

Hogg, M. A. (2006). Social identity theory. In P. J. Burke (Ed.), Contemporary social psychological theories (pp. 111-128). Stanford, CA: Stanford University Press.

Hogg, M. A., \& Williams, K. D. (2000). From I to we: social identity and the collective self. Group Dynamics: Theory, Research and Practice, 4(1), 81-97. doi: 10.I037//1089-2699.4.1.81 
Holmgren, L. E., \& Hearn, J. (2009). Framing 'men in feminism': Theoretical locations, local contexts and practical passings in men's gender-conscious positionings on gender equality and feminism. Journal of Gender Studies, 18(4), 403-418. doi:10.1080/09589230903260076

hooks, b. (2000a). Feminism is for everybody: Passionate politics. Cambridge, MA: South End Press.

hooks, b. (2000b) Feminist theory: From margin to center. Cambridge, MA: South End Press.

Hooper, C. (2001) Manly states: Masculinities, international relations, and gender politics. New York: Columbia University Press.

Jackson, L. A., Fleury, R. E., \& Lewandowski, D. A. (1996). Feminism: Definitions, support, and correlates of support among female and male college students. Sex Roles, 24(9-10), 687-693. doi: 10.1007/BF01551502

Kearney, M. C. (2012). Introduction. In M. C. Kearney (Ed.), The gender and media reader, (pp. 1-13). London: Routledge.

Kelly, C. \& Breinlinger, S. (1995). Identity and injustice: Exploring women’s participation in collective action. Journal of Community \& Applied Social Psychology, 5(1), 41-57. doi: 10.2307/2786799

Klandermans, B., Sabucedo, J. M., Rodriguez, M., \& De Weerd, M. (2002). Identity processes in collective action participation: Farmers' identity and farmers' protest in the Netherlands and Spain. Political Psychology, 23(2), 235-251. Retrieved from http://www.jstor.org.proxy.lib.pdx.edu/stable/3792289 
Kimmel, M. (2005). Masculinity as homophobia, fear, shame, and silence in the construction of gender identity. In Gender of desire: Essays on male sexuality (pp. 25-42). Ithaca, NY: State University of New York Press.

Kinser, A. E. (2004). Negotiating spaces for/through third-wave feminism. NWSA journal, 16(3), 124-153. Retrieved from https://muse.jhu.edu/article/175042

Le Masurier, M. (2011). Reading the Flesh: Popular feminism, the second wave and Cleo's male centrefold. Feminist Media Studies, 11(2), 215-229. doi: $10.1080 / 14680777.2010 .521628$

Liss, M., Crawford, M., \& Popp, D. (2004). Predictors and correlates of collective action. Sex Roles, 50(11-12), 771-779.

Lorber, J. (1991). The social construction of gender. Newbury Park, CA: Sage.

Lorber, J. (1994). 'Night to his day': The social construction of gender. In Paradoxes of gender (pp. 13-36). New Haven, CT: Yale University Press.

Lotz, A. D. (2003). Communicating third-wave feminism and new social movements: Challenges for the next century of feminist endeavor. Women and language, 26(1), 2-10. Retrieved from http://go.galegroup.com.proxy.lib.pdx.edu/ps/i.do?p=PPCM\&sw=w\&u=s1185784 $\& v=2.1 \& \mathrm{it}=\mathrm{r} \& \mathrm{id}=\mathrm{GALE} \%$ 7CA106941803\&asid=9fa7e66b9c2359b894falc1918d fde6f

Lumby, C. (2014). Post-postfeminism. In C. Cart, L. Steiner, \& L. McLaughin (Eds.), The Routledge companion to media and gender (pp. 600-609). New York: Routledge. 
Mahalik, J. R. (2007). Masculinity and perceived normative health behaviors as predictors of men's health behaviors. Social Science \& Medicine, 64(11), 22012209. doi: 10.1016/j.socscimed.2007.02.035

Mann, S. A., \& Huffman, D. J. (2005). The decentering of second wave feminism and the rise of the third wave. Science \& Society, 69(1), 56-91.

McCabe, J. (2005). What's in a label?: The relationship between feminist selfidentification and "feminist" attitudes among U.S. women and men. Gender \& Society, 19(4), 480-505. doi: 10.1177/0891243204273498

Modleski, T. (1991). Feminism without women. New York: Routledge.

Morgan, D. L. (1988). Focus groups as qualitative research. London: Sage.

Morgan, D. L. (1997). Focus groups as qualitative research. London: Sage.

Pratt, M. G. (2008). Fitting oval pegs into round holes: Tensions in evaluating and publishing qualitative research in top North American Journals. Organizational Research Methods, 11, 481-509. doi: 10.1177/1094428107303349

Pew Research Center, Washington D.C. (2016). Millennials overtake baby boomers as America's largest generation. Retrieved from http://www.pewresearch.org/facttank/2016/04/25/millennials-overtake-baby-boomers/

Pussyhat Project, (n.d.). FAQ. Retrieved from https://www.pussyhatproject.com/faq/ Pussyhat Project, (2016). Our story. Retrieved from https://www.pusshatproject.com/ourstory/

Rubin, H. J., \& Rubin, I. S. (1995). Qualitative interviewing: The art of hearing data. Thousand Oaks, CA: Sage. 
Ryan, B. (1992). Feminism and the women's movement. New York: Routledge.

Sandelowski, M., Voils, C. I., \& Knafl, G. (2009). On quantitizing. Journal of mixed methods research, 3(3), 208-222. doi: 10.1177/1558689809334210

Snyder, R. C. (2008). What Is Third-Wave Feminism? A New Directions Essay. Signs, 34(1), 175-196. doi: 10.1086/588436

Suter, E. A., \& Toller, P. W. (2006). Gender role and feminism revisited: A follow-up study. Sex Roles, 55, 135-146. doi: 10.1007/s11199-006-9065-4

Springer, K. (2002). Third wave black feminism?. Signs, 27(4), 1059-1082. doi: $10.1086 / 339636$

Stewart, D. W., Shamdasani, P. N., \& Rook, D. W. (2007). Group dynamics and focus group research. In Focus Groups (pp. 19-37). Thousand Oaks, CA: Sage.

Szymanski, D. M. (2004). Relations among dimensions of feminism and internalized heterosexism in lesbians and bisexual women. Sex Roles, 51(3-4), 145-159. doi: 10.1023/B:SERS.0000037759.33014.55

Tajfel, H., \& Turner, J. C. (1979). An integrative theory of intergroup conflict. In W. G. Austin \& S. Worchel (Eds.), The social psychology of intergroup relations, (pp. 33-47). Monterey, CA: Brooks/Cole.

Tarrant, S. (2009). Men and feminism. Berkeley, CA: Seal Press.

Toller, P. W., Suter, E. A., Trautman, T. C. (2004). Gender role identity and attitudes toward feminism. Sex Roles, 51(1/2), 85-90. 
Twenge, J. M., \& Zucker, A. N. (1999). What is a feminist? Closed and open-ended responses. Psychology of Women Quarterly, 23(3), 591-605. doi: 10.1111/j.14716402.1999.tb00383.x

Vagianos, A. (2016, October 17). Young male athletes push back on 'locker room banter' in one viral photo. The Huffington Post. Retrieved from http://www.huffingtonpost.com/entry/male-athletes-push-back-on-locker-roombanter-in-one-viral-photo_us_5804edcae4b06e047595ec6b

Vaismoradi, M., Jones, J., Turunen, H., \& Snelgrove, S. (2016). Theme development in qualitative content analysis and thematic analysis. Journal of Nursing Education and Practice, 6(5), 100-110. doi: 10.5430/jnep.v6n5p100

Vaismoradi, M., Turunen, H., \& Bondas, T. (2013). Content analysis and thematic analysis: Implications for conducting a qualitative descriptive study. Nursing and Health Sciences, 15(3), 398-405. doi: 10.1111/nhs.12048

van Stekelenburg, J., \& Klandermans, B. (2013). The social psychology of protest. Current Sociology Review, 61(5-6), 886-905. doi: 10.1177/0011392113479314 van Zomeren, M., Postmes, T., \& Spears, R. (2008). Toward an integrative social identity model of collective action: A quantitative research synthesis of three sociopsychological perspectives. Psychological bulletin, 134(4), 504-535. doi: 10.1037/0033-2909.134.4.504

Vick, K. (2017, January). Perhaps the largest protest in U.S. history was brought to you by Trump. Times Magazine. Retrieved from http://time.com/4649891/protestdonald-trump/ 
WHAT'S NEW PUSSYHAT?

Washington Post-Kaiser Family Foundation. (2015). Feminism in the U.S. [Data file and code book]. Retrieved from https://www.washingtonpost.com/apps/g/page/national/washington-post-kaiserfamily-foundation-poll-feminism-in-the-us/1946/

Wiley, S., Srinivasan, R., Finke, E., Firnhaber, J., \& Shilinsky, A. (2012). Positive portrayals of feminist men increase men's solidarity with feminists and collective action intentions. Psychology of Women Quarterly, 37(1), 61-71. doi:10.1177/0361684312464575

Wilkinson, S. (1998). Focus groups in feminist research: Power, interaction, and the coconstruction of meaning. Women's Studies International Forum, 21(1), 111-125. doi: $10.1016 / \mathrm{S} 0277-5395(97) 00080-0$

Williams, R., \& Wittig, M. A. (1997). "I'm not a Feminist, but...": Factors contributing to the discrepancy between pro-feminist orientation and feminist social identity. Sex Roles, 37(11/12), 885-904. doi: 10.1007/BF02936345

Women's March, (n.d.). Mission statement. Retrieved from https://www.womensmarch.com/mission/

Zucker, A. N. (2004). Disavowing social identities: What it means when women say, "I'm not a feminist, but...". Psychology of Women Quarterly, 28(4), 423-435. doi: 10.1111/j.1471-6402.2004.00159.x

Zucker, A. N., \& Bay-Cheng, L. Y. (2010). Minding the gap between feminist identity and attitudes: The Behavioral and ideological divide between feminists and non- 
labelers. Journal of Personality, 78(6), 1895-1924. doi: 10.1111/j.14676494.2010.00673.x 
Appendix A: Recruitment Script

\section{$\underline{\text { Recruitment script }}$}

Thank you for allowing me time to present you with this opportunity. I am conducting a research study on the public's perceptions about social issues as part of a master's thesis under the supervision of Dr. Frank.

Participants in this study should be men, 18-35 years of age. Participation in this study is completely voluntary, and we will keep your identity confidential. There are minimal risks associated with participating, as you might feel uncomfortable sharing information regarding your feelings about current social issues. Overall, risks associated are less than one would experience in everyday life. Choosing to participate or choosing not to participate will NOT negatively impact your course grade in any way. If you choose to participate in this study, you will participate in a focus group in exchange for extra credit in this course. The activity shouldn't take more than 1.5 hours.

If you choose not to participate in this focus group, are not eligible survey or decide to withdraw early, you will have the option to complete an alternate extra credit assignment, and should contact me or follow the instructions on the end of the pre-screening survey.

If you would like to participate in this study, please go to the following web address and complete the online pre-screening survey. The link to this pre-screening survey will also be provided on the D2L page for this course.

If you have any questions, feel free to contact the researcher, Rachel Crist at rcrist@pdx.edu.

If you have questions or concerns about your rights as a research subject, please contact the Portland State University Institutional Review Board.

\section{PSU Institutional Review Board Office of Research Integrity 1600 SW 4th Ave., Market Center Building, Ste. 620 Portland, OR 97201 (503) 725-2227 or 1 (877) 480-4400}

Thank you for your time. Your participation is greatly appreciated. 
Appendix B: Pre-Screening Survey

Thesis Screener

Q1.1 Informed Consent Form: You are invited to participate in a pre-screening survey

for a study conducted by Rachel Crist under the direction of Dr. Frank for a Master's Degree Thesis at Portland State University. This pre-screening survey will determine your eligibility to take part in a focus group study on perceptions of social issues. This pre-screening survey will collect basic demographic information as well as ask for your affiliation with a number of social issues. Those not selected to participate in the study will be given information regarding an alternative extra-credit assignment. You were selected as a possible participant in this study because you are enrolled as an undergraduate in a communication course.

Procedures: If you decide to participate, you will be asked to complete the following pre-screening survey. The survey will take approximately 5 minutes or less.

Risks/Discomforts: Risks are minimal for involvement in this study. However, you may feel uncomfortable when asked to share information about your perceptions of social issues. You are welcome to skip any question that you feel uncomfortable answering. Benefits: You may not receive any direct benefit from taking part in this study. However, it is hoped that through your participation, the study may help to increase knowledge which may help others in the future.

Confidentiality: All information that is obtained in connection with this study will be kept confidential and will only be reported in an aggregate format (by reporting only combined results and never reporting individual ones). All surveys will be concealed, and no one other than the research team will have access to them. At no point will you name be linked to your answers.

Compensation: You may earn academic extra credit for your participation. Follow the directions at the end of the survey. Extra credit will be assigned based on either participation in the study or completion of an alternative extra credit assignment.

Participation: Participation in this research study is completely voluntary. You have the right to withdraw at any time or refuse to participate entirely, and it will not affect your course grade in the class or standing with the university. If you wish to receive extra credit but do not wish to complete the survey, contact the researcher for an alternative extra credit opportunity.

Questions about the Research: If you have questions or concerns regarding this study, contact Rachel Crist at rcrist@pdx.edu or Dr. Lauren Frank at 1frank@pdx.edu.

Questions about your Rights as Research Participants: If you have questions or concerns about your rights as a research subject, please contact the Portland State University Institutional Review Board.

PSU Institutional Review Board

Office of Research Integrity

1600 SW 4th Ave., Market Center Building, Ste. 620

Portland, OR 97201

(503) 725-2227 or 1 (877) 480-4400 
By completing this survey, you are certifying that you are 18 years of age or older, that you have read and understand the above information and agree to take part in the prescreening survey. Print to keep a copy of this form for your own records. If at this point you choose to continue in the pre-screening for this study, please click " $>>$ " to continue.

Q1.2 What is your gender?

O Male (1)

Female (2)

Other (3)

Q1.3 What year were you born?

O $2000(1)$

○ ...

O $1940(61)$

Q2.1 Thank you for your interest in participating in this study. You were not selected to participate and are instead eligible for extra credit by completing the following assignment. Details are listed below. Completed extra credit should be attached as a word document in an email to Rachel Crist at rcrist@pdx.edu. Any questions concerning the extra credit assignment should be directed to Rachel Crist at rcrist@pdx.edu.

Q3.1 Please indicate your level of support for the following social issues.

\begin{tabular}{|c|c|c|c|c|}
\hline & $\begin{array}{l}\text { Strongly } \\
\text { against (1) }\end{array}$ & $\begin{array}{l}\text { Moderately } \\
\text { against (2) }\end{array}$ & $\begin{array}{l}\text { Moderately for } \\
\text { (3) }\end{array}$ & $\begin{array}{l}\text { Strongly for } \\
\text { (4) }\end{array}$ \\
\hline $\begin{array}{c}\text { Environmental } \\
\text { Justice (1) }\end{array}$ & $\mathrm{O}$ & $\mathrm{O}$ & $\mathrm{O}$ & $\bigcirc$ \\
\hline $\begin{array}{c}\text { Black Lives } \\
\text { Matter (2) }\end{array}$ & $\mathrm{O}$ & $\bigcirc$ & $\bigcirc$ & $\mathrm{O}$ \\
\hline Pro-Choice (3) & $O$ & $O$ & $O$ & $O$ \\
\hline Feminism (4) & O & $\mathrm{O}$ & $\mathrm{O}$ & $\bigcirc$ \\
\hline Pro-Life (5) & $\mathrm{O}$ & O & O & O \\
\hline $\begin{array}{c}\text { LGBTQ Rights } \\
\text { (6) }\end{array}$ & $\mathrm{O}$ & $\bigcirc$ & $\mathrm{O}$ & $\bigcirc$ \\
\hline $\begin{array}{c}\text { Death Penalty } \\
\text { (7) }\end{array}$ & $\mathrm{O}$ & O & $\mathrm{O}$ & $\bigcirc$ \\
\hline
\end{tabular}


Q3.2 I identify as... (Please mark "yes" for all that apply).

\begin{tabular}{|c|c|c|}
\hline & Yes (1) & No (2) \\
\hline Feminist (1) & $\mathrm{O}$ & $\mathrm{O}$ \\
\hline Pro-Choice (2) & $\mathrm{O}$ & $\mathrm{O}$ \\
\hline Pro-Life (3) & $\mathrm{O}$ & $\mathrm{O}$ \\
\hline Environmentalist (4) & $\mathrm{O}$ & $\mathrm{O}$ \\
\hline LGBTQ Ally (5) & $\mathrm{O}$ & $\mathrm{O}$ \\
\hline Gay/Lesbian (6) & $\mathrm{O}$ & $\mathrm{O}$ \\
\hline Trans (7) & $\mathrm{O}$ & $\mathrm{O}$ \\
\hline Bisexual/Queer (8) & $\mathrm{O}$ & $\mathrm{O}$ \\
\hline Conservative (9) & $\mathrm{O}$ & $\mathrm{O}$ \\
\hline Liberal (10) & O & $\mathrm{O}$ \\
\hline Other (Please specify) (11) & $\mathrm{O}$ & $\mathrm{O}$ \\
\hline
\end{tabular}

Q4.1 Please indicate all days and times for which you are available below.

\begin{tabular}{|l|l|l|}
\hline & Yes (1) & No (2) \\
\hline DAY TIME OPTION 1 (1) & O & O \\
DAY TIME OPTION 2 (2) & O & O \\
DAY TIME OPTION 3 (3) & O & O \\
DAY TIME OPTION 4 (4) & O & O \\
\hline
\end{tabular}

Q14 Please provide your full name so your answers can be matched to your participation in the focus groups. Please note that this is for the sole purpose of matching your survey response with your participation in the focus groups. Once data collection has been completed, all identifiers will be removed before use in the study findings.

Q13 Please provide your email address so that you can be contacted regarding focus group scheduling. 
Appendix C: Moderator's Guide

Moderator: Hello and welcome. Thank you for coming today. Before we begin we will establish a few ground rules. All of the information that you provide us here will be confidential. In order to assist us maintaining confidentiality, please do not discuss it afterwards.

It is important that you do not leave the room unless absolutely necessary. Please silence your cell phones and put them away so that we do not have any interruptions; you can go ahead and do this now if you haven't already.

This will be in a conversation format that allows you to share your experience as well as reply to what other participants share. Everyone is encouraged to participate and share in this discussion. Please know that you are not obligated to share anything you do not feel comfortable sharing. We are holding this conversation to learn from you, so please be sure to express yourself honestly. When one person is talking, please wait until they are finished.

To assist us in the transcription of this conversation, we have two audio recorders set up so that we are sure not to lose any information. Do you agree for us to record this conversation? If you agree, I need for you to tell me you are in agreement. Can we go around the table and have you state your pseudonym and whether you agree to be audio recorded?

Moderator:

Q1: How do you define feminism? (RQ3)

P: What do you feel are the goals of feminism?

P: What do you think are other social issues of concern for feminists?

P: How did you learn about feminism? What prompted you to learn about feminism? (RQ1, RQ3)

Q2: Using your own understanding of feminism, what qualities make someone a feminist? (RQ2)

P: How does a feminist act?

Q3: What do you think of feminists? (RQ3)

Q4: How can men participate in feminism? (RQ1)

P: What sort of behavior would you consider typical of a feminist man?

P: What reasons might a man have for being a feminist?

Q5: How do you think men who call themselves feminists are viewed? (RQ2)

P: How do you think women perceive male feminists?

Q6: How are men affected by feminism? (RQ3, RQ1)

Concluding script: Thank you all for your time and contributions today. I would like to remind you that the participants and the discussion that took place within this focus group should not be discussed with anyone outside of the study. 